\title{
Cytokines in Male Fertility and Reproductive Pathologies: Immunoregulation and Beyond
}

\begin{abstract}
Kate L. Loveland 1,2,3*, Britta Klein ${ }^{4,5}$, Dana Pueschl1,2,4, Sivanjah Indumathy 1,2,4, Martin Bergmann ${ }^{4}$, Bruce E. Loveland ${ }^{6}$, Mark P. Hedger ${ }^{1,2}$ and Hans-Christian Schuppe ${ }^{7}$
\end{abstract}

OPEN ACCESS

Edited by:

Pierre De Meyts,

de Duve Institute, Belgium

Reviewed by:

Ilpo Huhtaniemi,

Imperial College London,

United Kingdom

David H. Volle,

Institut national de la santé et de la recherche médicale, France

*Correspondence:

Kate L. Loveland

kate.loveland@monash.edu

Specialty section: This article was submitted to Molecular and Structural Endocrinology,

a section of the journal

Frontiers in Endocrinology

Received: 17 August 2017 Accepted: 23 October 2017 Published: 20 November 2017

Citation:

Loveland KL, Klein B, Pueschl D,

Indumathy S, Bergmann M,

Loveland BE, Hedger MP and

Schuppe H-C (2017)

Cytokines in Male Fertility and

Reproductive Pathologies: Immunoregulation and Beyond.

Front. Endocrinol. 8:307. doi: 10.3389/fendo.2017.00307
Germline development in vivo is dependent on the environment formed by somatic cells and the differentiation cues they provide; hence, the impact of local factors is highly relevant to the production of sperm. Knowledge of how somatic and germline cells interact is central to achieving biomedical goals relating to restoring, preserving or restricting fertility in humans. This review discusses the growing understanding of how cytokines contribute to testicular function and maintenance of male reproductive health, and to the pathologies associated with their abnormal activity in this organ. Here we consider both cytokines that signal through JAKs and are regulated by SOCS, and those utilizing other pathways, such as the MAP kinases and SMADs. The importance of cytokines in the establishment and maintenance of the testis as an immune-privilege site are described. Current research relating to the involvement of immune cells in testis development and disease is highlighted. This includes new data relating to testicular cancer which reinforce the understanding that tumorigenic cells shape their microenvironment through cytokine actions. Clinical implications in pathologies relating to local inflammation and to immunotherapies are discussed.

Keywords: cytokines, testis cancer, immune cells, macrophages, spermatogenesis, infertility, spermatogonial stem cells, male reproductive health

\section{INTRODUCTION}

\section{The Contributions of Cytokines to Testicular Functions and Health}

Male fertility requires the production of functional sperm in sufficient numbers to achieve fertilization. Although the means by which this is accomplished varies between species, the processes essential for emergence of a haploid gamete with the capacity to fertilize an oocyte and contribute to healthy offspring are highly conserved. Germline development in vivo is dependent on the environment formed by somatic cells and the differentiation cues they provide. Knowledge of how somatic and germline cells interact is central to achieving biomedical goals relating to restoring, preserving, or restricting fertility in humans. Technical challenges related to understanding the 
dynamic and complex signals restrict progress toward these outcomes and have also hampered efforts to establish in vitro gametogenesis.

This review highlights the importance of cytokines in testis development and function that relate generally to fertility and pathology. The definition of cytokines as short-acting, shortlived signaling molecules that regulate cell functions is used here, including those that signal through JAKs and are regulated by SOCS and those utilizing other pathways, such as the MAP kinases (MAPKs). Particular areas of current research interest are highlighted relating to the likely roles of immune cells in testis development and disease. This includes new data relating to testicular cancer which reinforce the understanding that tumorigenic cells shape their microenvironment through cytokine actions.

\section{Cellular Architecture of the Testis}

Conventionally, the adult mammalian testis is considered to produce two key products, sperm, and testosterone. These are synthesized in structurally distinct compartments, the seminiferous tubules and the interstitial space [Figure 1; for comprehensive review, see Ref. (1)]. Sertoli cells form the structural platform of the seminiferous tubules within which all stages of spermatogenesis occur. The tubules are completely surrounded by peritubular myoid cells, which together with Sertoli cells synthesize a basement membrane upon which sperm precursor cells, the mitotic spermatogonia, reside. Immune cells, especially a subset of macrophages and, in human testes, a few scattered mast cells, are also found in close apposition to the tubule perimeter. Testosterone is produced by the Leydig cells, which reside in the interstitium, in close apposition to immune cells, including macrophages, fibroblasts, and both lymphatic and blood vessels. In adult animals, the mitotically dividing and progressively maturing germline precursor cells, spermatogonia, transition through meiosis as spermatocytes and develop into haploid spermatozoa, continuously embedded within the seminiferous epithelium formed by post-mitotic, columnar Sertoli cells. The least mature, mitotic spermatogonial stem cells (SSC) and their differentiated progeny are located at the base of the seminiferous tubule in postpubertal animals, with progressively more mature germ cell types found moving toward the tubule lumen (Figure 1). Tight

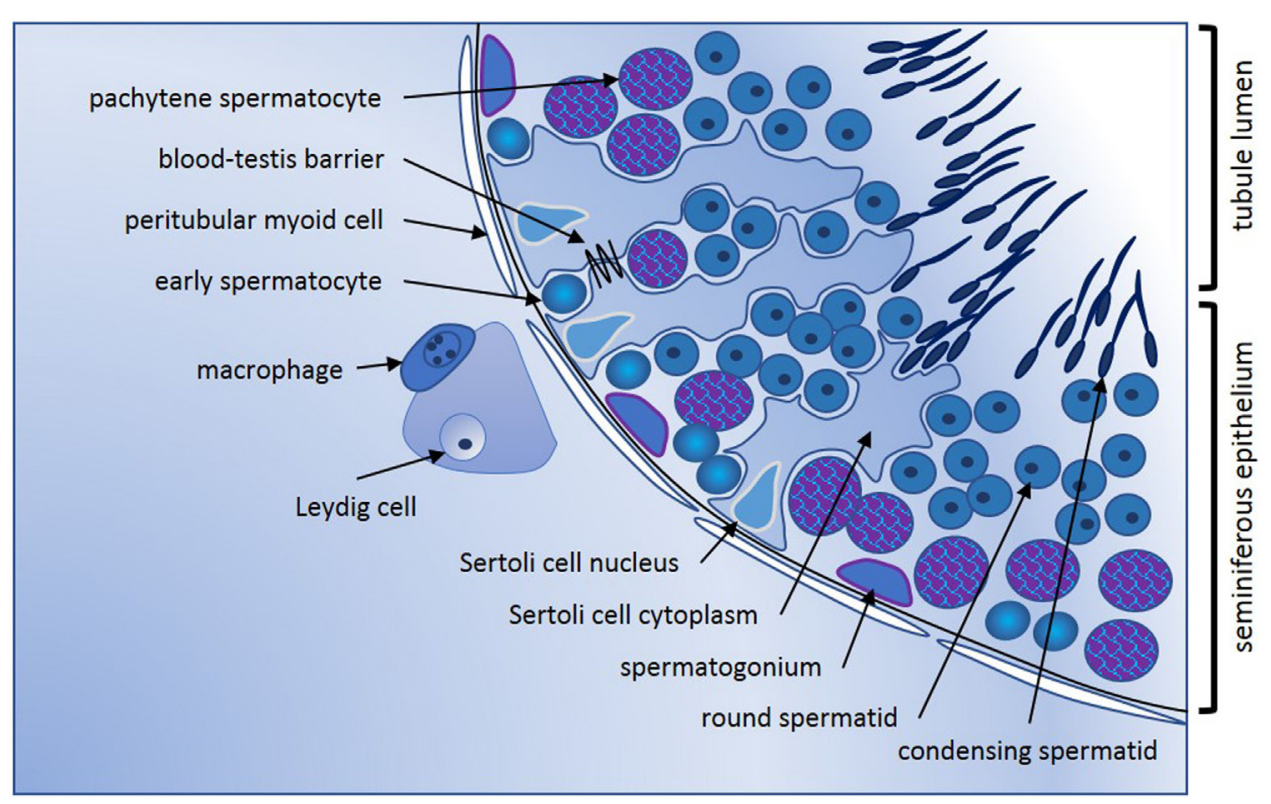

FIGURE 1 | Seminiferous epithelium illustrating spermatogenic progression and indicating the key cell types. Formation of spermatozoa occurs within the seminiferous epithelium of the adult testis, which is formed by columnar Sertoli cells. Every stage of spermatogenic cell, from the least mature spermatogonia at the base, to the haploid elongating spermatid, is closely connected to or embedded within the Sertoli cells that create the epithelial architecture and provide nourishment and maturation cues essential for tight regulation of male germline maturation. Tight junctions between adjacent Sertoli cells first form the blood-testis barrier at puberty with the onset of meiosis and are vital for maintenance of spermatogenesis. Sertoli cells form the lumen of the seminiferous tubules via apical secretion, creating a passageway for release and transport of spermatozoa into the epididymis for additional maturation that is essential to fertility. Completely surrounding the tubules are one or more continuous layers of peritubular myoid cells. These have contractile properties that facilitate spermatozoal movement to excurrent ducts, they collaborate with Sertoli cells to generate the basement membrane which spermatogonia contact, and they synthesize other factors that influence germline development and testis function. Progressively maturing spermatogenic cells move from the tubule base toward the lumen; cells entering meiosis (early spermatocytes) lose contact with the basement membrane and pass through the Sertoli cell tight junctions into the apical compartment of the epithelium. Late stage spermatocytes complete the two meiotic divisions to become the haploid spermatids that transform from round to elongated spermatids that develop the microtubule-based tail and a head containing the highly compacted chromatin and anterior acrosomal vesicle present in spermatozoa. Leydig cells are the most abundant cell type in the interstitium; they produce testosterone that is vital for spermatogenesis and for male secondary characteristics. Blood and lymphatic vessels serve as conduits for hormonal signals that regulate testicular functions, while macrophages and mast cells are found both in close proximity to Leydig cells between the tubules, and closely opposed to peritubular cells. 
junctions between adjacent Sertoli cells form first at the onset of puberty, marking the end of the rapid increase in somatic cell populations. These junctions separate post-meiotic germ cells (spermatids) from the immune cells present in peri- and inter-tubular (interstitial) spaces, preventing immune cell recognition of these "developmentally late" reproductive cells as foreign.

\section{The Complexity of Cytokine Signaling Pathways in the Testis: Many Advances and Many Knowledge Gaps}

Much of our knowledge of cytokine structure, signaling pathways, and function relates to their involvement in immune cell activity. While many factors, such as interleukins and tumor necrosis factor (TNF), control immune cell function within the testis, they also are produced by "non-immune cells" to stimulate and maintain spermatogenesis. The initial interest of testicular biologists in the roles of cytokines arose with the discovery that rat testicular extracts contained interleukin-1 (IL1), which was then shown to be produced by Sertoli cells rather than by intra-testicular leukocytes $(2,3)$. This discovery provided the first indication that an inflammatory cytokine, traditionally associated with immune reactions, was produced by a somatic cell of the male reproductive system when there was no evidence of immune stimulation. It subsequently became apparent that many so-called pro-inflammatory and immunoregulatory cytokines were being produced by testicular somatic and spermatogenic cells, both under normal conditions and in response to inflammatory stimuli (4).

Several interleukin family cytokines, such as interleukin-6 (IL6) and IL10, signal through cell surface receptors that feature intracellular binding sites for JAK family kinases. Upon ligand binding, the phosphorylation of STAT proteins mediates signal transduction to the nucleus to effect changes in gene activity. STAT recruitment and activation are controlled by cytoplasmic SOCS proteins. Other cytokines share the capacity for shortacting, short-lived signaling and are essential for male fertility but do not signal through the JAK/STAT pathway. These include IL1, which signals via the adapter protein MyD88 to activate the inflammatory transcription factor, $\mathrm{NF \kappa B}$, and members of the transforming growth factor-beta (TGF $\beta$ ) superfamily, such as TGF $\beta$ s and activins, which signal through serine/threonine kinase receptor subunits to activate SMAD transcription factors. Several of these cytokines were first isolated and characterized as reproductive hormones and their roles in immune signaling were discovered later. Chemokines involved in core developmental events, including CXCL12, are also essential for specific stages of germline maturation, as described below. Signaling pathway cross-talk is increasingly recognized to influence signaling outcomes [e.g., Ref. $(5,6)$ and reviewed in Ref. (7)], and although their specific relevance to testicular physiology is poorly understood, this is an area of intense current interest. For many cytokines present within the testis, fundamental knowledge regarding their sites of synthesis, target cells, and what regulates their production and activity remains to be revealed.

\section{CYTOKINES IN THE NORMAL TESTIS}

\section{Diverse Cytokines and Functions Are Essential to Support Germ Cells: Which Ones Matter?}

Important aspects of normal testis development and function are modulated or driven by cytokine activities. There is accumulating knowledge of immune cell-associated cytokines essential for fertility that maintain testicular homeostasis within the complex and dynamic environment of the seminiferous epithelium. Because cytokines are key mediators of immune cell function, and because the testis is a tissue in which cytokine functions are tightly regulated to protect and allow sperm production, there is a strong motivation to identify those present in the testis and to determine how they work. It is also important to recognize that cytokine production from non-immune cells is central to normal adult testis functions.

For example, both Sertoli and Leydig cells can be stimulated to produce large amounts of the immunoregulatory cytokine, IL6, driven at least in part by endogenous IL1. Both IL1 and IL6 are able to regulate Sertoli cell and spermatogenic cell development (4). Spermatogenic cells produce TNF. It has dual actions as a signaling molecule, to regulate Sertoli cell function and cell death, in response to toxic insults, and this activity is largely determined by the receptor with which it interacts (8).

Several members of the TGF $\beta$ superfamily provide developmentally regulated and cell-specific signals essential for normal testis development and fertility [reviewed in Ref. $(9,10)$ ]. The activin A homodimer was identified on the basis of its formation from the $\beta A$ subunits of the gonadal hormone inhibin. It was shown to be a testicular cytokine around the same time as IL1, but it took many years for this product of Sertoli and other somatic cells to be recognized as also serving immune modulatory functions. The canonical members of the superfamily, TGF $\beta 1-3$, are involved in many aspects of inflammation and immunoregulation (11), and like activin are produced by several testicular somatic cell types to regulate germline and somatic cell growth and activity $(9,12-15)$.

Colony-stimulating factor-1 (CSF1) and macrophage migration inhibitory factor (MIF) are developmental cytokines with central roles in macrophage recruitment and functional maturation. They are most closely associated with regulating macrophage and Leydig cell development within the testis; CSF1-deficient mice, although fertile, have severe hypospermatogenesis and are androgen deficient due to poor development of the testicular macrophage and Leydig cell populations $(16,17)$. The role of CSF1 in spermatogonial maintenance has been demonstrated in the adult mouse testis (18).

Interferons (IFN; $\alpha, \beta$, and $\gamma$ ) are produced by many testicular cells, particularly somatic cells, and especially during viral infections. While these are implicated in protecting the testis from virus infection, there is evidence that interferons regulate Sertoli cell and Leydig cell function as well $(19,20)$. The first chemokine identified in the testis was MCP-1/CCL2, which is implicated in regulation of the large testicular macrophage population $(21,22)$. 
With the diversity of signaling molecules simultaneously present within the seminiferous epithelium, what are the mechanisms by which both maintenance and continuous maturation of stem cells into spermatozoa are supported? The cycle of the seminiferous epithelium is the basis for ongoing sperm production, in which spermatogenic development is linked vertically within a Sertoli cell and conserved subsets of differentiating germ cells are observed in each cross section of a seminiferous tubule. Several cytokines, including IL1, IL6, TNF, and activin A, are produced by the Sertoli or spermatogenic cells in a cyclical manner during the maturation cycles of the seminiferous epithelium, suggesting that their actions are central to regulating this fundamental feature of testicular functions (23). Their detection in distinct seminiferous tubule cross sections of the adult testis reflects their temporally regulated synthesis and function. Other data also indicate that they serve key roles in inter-compartmental intercellular communication, regulation of steroidogenesis, and immunoregulation, including immune privilege, while also contributing to pathophysiology and the detrimental effects of inflammatory responses on testis function. Many of these aspects have been previously reviewed (23-25). In the following sections, some key examples of developmental processes and pathologies of the testis that are influenced by specific cytokines, but which have received less attention to date, are provided.

\section{Cytokine Signaling in Germline Cells JAK/STAT Signals in Testicular Stem Cells}

The vital contribution of JAK-STAT signaling to Drosophila germline stem cell maintenance occurs within the somatic stem cells that form the germline niche. Activation of this pathway promotes endogenous production of its inhibitor, SOCS36E, restricting growth of the niche cells (termed "the hub") and thereby enabling spermatogonia stem cells to survive (26). The level of this signaling provides the numerical balance between somatic and germ cells, because both require access to integrins in the basement membrane for survival. Thus, appropriate pathway activation is required to create the germline:niche cell ratio required to support spermatogenesis and normal fertility. Central to this process is regulation of SOCS36E in the niche cells, which is involved in controlling downstream MAPK activity (27). Additional mechanisms implicated in control of JAK-STAT signaling within germline cells involve Wnt-2 and a $\mathrm{H} 3 \mathrm{~K} 4 \mathrm{me} 3$ histone demethylase, encoded by lid (28-30). An important outcome of pathway activation in the germline is enhanced male stem cell survival. Mediated by the downstream target, DIAP1 (31), this includes sex-specific activation of a male gene, $P h f 7$. Intriguingly, inappropriate $P h f 7$ expression in females is associated with the formation of germline tumors (32). These and other studies from the Matunis laboratory $(33,34)$ demonstrate that the impact of this pathway, which is central to fertility, is manifest in multiple cell types and in different stages of testicular development in the fly.

Less information specific to Jak/Stat signaling is available from mammalian studies. Experiments using rodent primary testicular cells indicated JAK-STAT recruitment occurs in gonocytes of the newborn testis. Pathway activation via a cadherin isotype was implicated in the earliest stages of spermatogenesis, when male germ cells first enter the SSC and/or differentiation pathway (35), but details are limited. In Leydig cells, JAK-STAT recruitment was documented following erythropoietin activation (36). The crucial role of these signals in the fly testis provide a rationale for future investigations assessing conserved functions for JAKSTAT signaling in both germline and somatic cells of the mammalian testis. These early observations have paved the way for explorations involving data integration from transcriptional and proteomic profiling of testicular cells to determine the expression profiles of particular cytokines and, therefore, their likely sites and timing of action.

\section{CXCL12 Control of the Male Germline \\ CXCL12 Acts on Primordial Germ Cells (PGCs)}

CXCL12 is a chemokine produced by somatic cells that influences early mammalian germline cells, including at stages considered of relevance for the initiation of testicular germ cell tumors (TGCTs). CXCL12 is produced as six different isoforms in humans, and different functions have been ascribed to these [reviewed in Ref. (37)].

Primordial germ cells and gonocytes both express the CXCL12 receptor, CXCR4, a seven-transmembrane protein which signals via G-proteins, leading to MAPK activation and to engagement of the phosphoinositol-3-kinase pathway. Somatic cell-production of CXCL12 facilitates the later stages of PGC migration into the genital ridge immediately prior to their sexual differentiation, and upon reaching the nascent gonad, CXCL12 supports gonocyte survival $(38,39)$. Mice lacking the CXCR4 receptor have fewer gonocytes, and the difference between wild type and mutant animals increases with developmental age, indicating that CXCL12 regulates the germline cell cycle in the fetal testis $(38,39)$. Studies of chick and zebrafish demonstrate this crucial function of supporting the earliest germ cell subtypes is evolutionarily conserved (40).

\section{CXCL12 Influences SSC Fate}

CXCL12-CXCR4 signaling is also central to mouse SSC fate $(41,42)$. The receptor is present in situ in the subpopulation of spermatogonia expressing markers of undifferentiated spermatogonia, and CXCR4 function is required for maximal colonization by spermatogonia transplanted into recipient gonads to assess their stem cell activity. In addition, CXCR4 transcript levels correlate directly with stimulation by glial cell line-derived growth factor (GDNF) and fibroblast growth factor 2 (FGF2), factors that sustain SSC functionality. Evidence that this signaling pathway in SSCs affects cell adhesion to the basement membrane was provided from a range of elegant transcriptome profiling, cell culture, and cell adhesion assays $(41,42)$, analogous to its functions in other stem cell systems.

As described above, PGCs and gonocytes express the CXCR4 receptor. In addition, the CXCR7 receptor protein that also binds CXCL12 is present on undifferentiated spermatogonia (43). Its specific role in germ cells is unclear, as CXCR7 serves variably as a decoy receptor and as a signaling receptor, to enhance and restrict cell responses to CXCL12 in different contexts [reviewed in Ref. (44)]. Evidence that all of these components perform conserved functions in the testis is provided from their expression profiles in the marmoset and human, which mirror those in the mouse (45). 
An additional cytokine that can signal through CXCR4 is MIF $(37,46)$. This widely expressed chemokine is often linked with pro-inflammatory events because of its role in the innate immune system, but it has also been linked with regulation of B lymphocyte migration (46). Early investigations of MIF in the rodent testis identified it as a Leydig cell product that could act on both Sertoli and peritubular cells to regulate their signaling $(47,48)$. Intriguingly, its production appeared to switch on in adult rat Sertoli cells in vivo when a toxicant was administered to achieve acute depletion of Leydig cells (47). A recent investigation of MIF function suggests that it may contribute to regulation of spermatogonial migration (49), which would be in accord with results of studies demonstrating this function for CXCR4 signaling $(41,42)$.

\section{Cytokines Function in Immune Regulation to Protect Germ Cells}

\section{Immune Privilege in the Testis}

In several mammalian tissues, such as the brain, eye, pregnant uterus, and testis, it is necessary to prevent immune responses against proteins that are normally hidden or are expressed late during development and which might become immunogenic autoantigens. The concept of "immune privilege" in these tissues relates to the mechanisms that underpin regulation of local cell function to prevent pathogenic autoimmunity (50). Haploid germ cells in the testis, in particular, express proteins that not subjected to the normal mechanisms of central tolerance, and strong adaptive immune reactions against these antigens can develop. This immune regulation is supported by the physical segregation of haploid germ cells, which develop only after puberty, away from direct contact with immune cells, as they become progressively more apically positioned within the seminiferous tubule epithelium (Figure 1). Sertoli cells actively phagocytose the residual haploid germ cell cytoplasm upon release of spermatozoa into the tubule lumen, and they have an important immunoregulatory function (51). Leydig and Sertoli cells support the immune privileged state by production of immunosuppressive molecules that include activin A, testosterone, PDL-1, Gas6, ProS, and TGF $\beta$ (Figure 2) (11, 50-52). In addition, certain germ cell types express FasL, which can bind to the Fas receptor, expressed by T-lymphocytes. This interaction may induce lymphocyte apoptosis to avoid cell activation (53). Immune cells within the healthy testis, most likely macrophages, are key contributors to the immunosuppressive milieu through their production of antiinflammatory cytokines, such as $\operatorname{IL} 10$ and $\operatorname{TGF} \beta(54,55)$, as discussed below. Without this control, presentation of testis-specific antigens on the surface of testicular macrophages and dendritic cells (DC) can lead to activation of T-lymphocyte responses and cellular or humoral immune reactions.

\section{Testicular Immune Cells under Physiological Conditions}

The normal mammalian testis contains diverse immune cells within the interstitial compartment, comprising resident

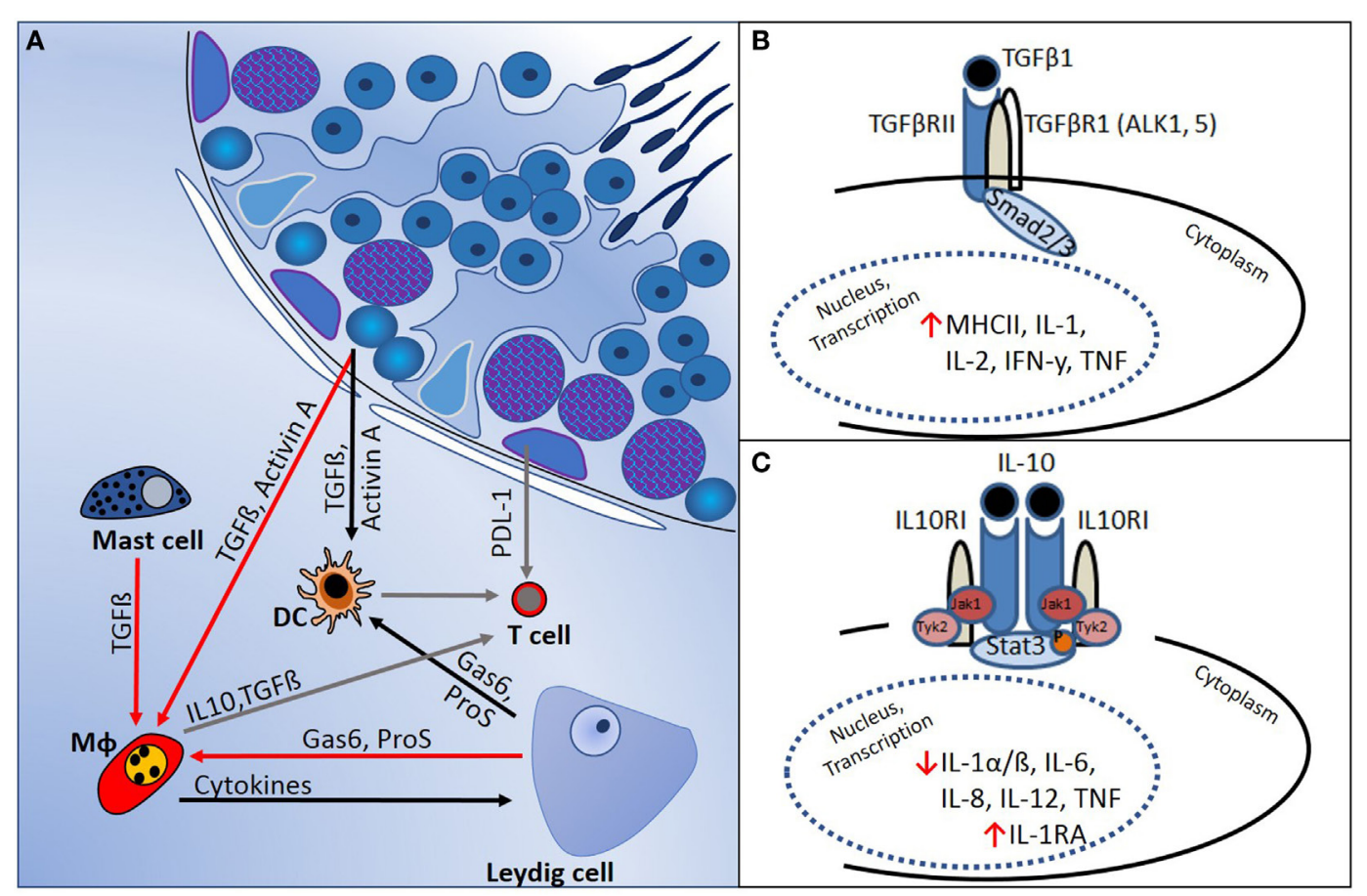

FIGURE 2 | Regulation of immune responses in the testis is mediated by a combination of structural and cellular-derived factors. (A) Production of cytokines and other immunoregulatory molecules by interacting cell types [mast cells, dendritic cells (DC), T cells, macrophages (M $\varphi$ ), and Leydig cells] in the testicular interstitial space creates an immunoregulatory environment, as outlined in the text. (B) TGF $\beta$-signaling via Smads 2 and 3 suppresses pro-inflammatory cytokine production and reduces cell-mediated immunity. (C) IL10 actions, mediated via JAK-STAT signaling, inhibit pro-inflammatory cytokines and induce anti-inflammatory responses (e.g., IL1RA production). 
macrophages, T-lymphocytes, DC, and mast cells (56-61). The numbers and distribution of immune cells differs between mammalian species, potentially reflecting differences in lifespan, functional activity, and exposure to pathogens.

The most abundant immune cell subtype in the testis is interstitial resident macrophages (62), most of which are physically closest to the interstitial Leydig cells $(63,64)$. Testicular macrophages arise from yolk-sac hemopoietic progenitors and are localized to the mesonephric region near the gonad border during early gonad sex differentiation (E10.5-E12.5) (65). They are essential for normal vascularization and testis cord formation in the fetal testis as well as Leydig cell development in the neonatal testis (17). In adult testes, transient depletion of testicular macrophages in a mouse model led to $75 \%$ reduction in total spermatogonial precursor number, revealing their vital importance in the regulation of the SSC niche (66).

Testicular macrophages comprise a heterogeneous population in the adult, based on cell-specific markers. Distinct interstitial macrophage subsets have been identified in the human and rat, which differentially express CD68 (a lysosomal glycoprotein) and CD163 (a cell surface glycoprotein member of the scavenger receptor cysteine-rich superfamiliy) $(56,58,61,67,68)$. In general, macrophages have highly variable properties and can either develop into M1 macrophages, which are classically activated and pro-inflammatory, or into M2 macrophages, which are alternatively activated and anti-inflammatory $(69,70)$. In mice, pro-inflammatory stimuli, such as bacterial lipopolysaccharides and IFN $\gamma$, lead to macrophage polarization toward M1 (70-72), whereas anti-inflammatory/immunoregulatory stimuli, such as IL4, IL10, IL13, TGF $\beta$, and glucocorticoids, polarize toward an M2 subpopulation [(73-76); reviewed in Ref. (77)]. The majority of testicular macrophages detected in rodents have an M2 phenotype $(54,68)$ and play important roles in maintenance of normal tissue homeostasis, fetal development, and immune response regulation. However, inflammation initiated by microbial pathogens or other immune events can also stimulate them to release pro-inflammatory cytokines, such as IL1, IL6, TNF and CCL2 $(22,70,71,78)$.

In healthy testis tissue, normal germ cell development is not impaired by the presence of the immune cells and their cytokines. Conversely, a change of immune homeostasis, associated with infection and inflammation, can lead to male infertility. In testicular germ cell neoplasia, there is strong evidence that the immune cell environment is severely disrupted. Respective pathological conditions are discussed in Sections "Cytokines in Testicular Pathologies" and "Knowledge of Testicular Cytokines Used to Address Key Clinical Issues.”

\section{CYTOKINES IN TESTICULAR PATHOLOGIES}

\section{Testicular Cancer}

\section{The Origin of TGCTs and Research Challenges}

Germ cell neoplasia in situ (GCNIS) cells are the pre-malignant precursor cells of TGCTs, the most common testis tumor type. They develop within the testicular niche from PGCs or their immediate male progeny, gonocytes, which fail to mature into spermatogonia [reviewed in Ref. (79)]. This outcome is part of the spectrum of disorders associated with an elevated risk of infertility, termed the testicular dysgenesis syndrome, or TDS (80). GCNIS cells are large and round, with a sparse cytoplasm; they are morphologically similar to gonocytes and express markers of primitive germline cells, including OCT4, NANOG, GDF3, KIT, and AP-2 $\gamma$. Their transformation into neoplastic cells appears linked to the hormonal changes of puberty, with the non-seminoma subtype typically detected in men between 17 and 30 years of age and seminomas more commonly identified in 25- to 40-year-olds. Seminomas are morphologically similar to GCNIS cells and express the same markers. A striking feature of these tumors in many patients is the presence of immune cell infiltrates, discussed below. Non-seminomas are heterogeneous, containing various differentiated tissue and cell types, undifferentiated embryonal carcinoma cells and cells resembling extraembryonic tissues; this subtype is more aggressive and clinically challenging.

The failure of early germ cells to differentiate, which is considered to underpin GCNIS formation, is thought to relate to a somatic environment deficiency potentially arising from genetic and/or environmental factors $(79,80)$. The subsequent development of GCNIS cells into either seminoma or non-seminoma TGCTs reveals their cellular plasticity. However, the mechanisms underlying GCNIS establishment and progression into either subtype are largely obscure, particularly because this process may take years to decades. Genome-wide association studies (GWAS) have most frequently identified KITL and KRAS alleles as the highest genetic risk factor (81), providing clues to processes or events that may enable inappropriate survival of germ cells that do not differentiate. Mice and other common laboratory animals do not develop TGCTs similar to those found in humans; the timespan from PGC formation to onset of spermatogenesis in a mouse is less than one month, while in humans this transformation typically lasts several years. As a consequence, studies addressing human GCNIS etiology, transformation into frank TGCTs, and mechanisms of metastasis are ethically and practically limited by the paucity of research materials. Although animal models inform us about fundamental processes of germline differentiation, important progress toward understanding testicular neoplasia requires access to patient samples, including archival and fresh specimens and derived cell lines.

\section{What Cytokines Contribute to the Emergence and Differentiation of TGCTs?}

Knowledge of rodent spermatogenesis (summarized in Section "CXCL12 Influences SSC Fate") led to the hypothesis that aberrant CXCL12 signaling may contribute to the "dedifferentiation" of PGCs into GCNIS cells. CXCL12 is known to mediate normal cell migration and is implicated in many neoplasias, including the overexpression of its canonical receptor, CXCR4, in various cancers $(5,6)$. The proposed involvement of CXCL12 in GCNIS to seminoma progression was based on the observation that the CXCR4 transcript level was generally higher in human seminoma samples than in those from healthy controls, whereas CXCL12 did not differ (82). Variable CXCR4 levels between testis tumor 
samples suggested responsiveness to CXCL12 may differ between individuals. However, no substantial differences in CXCL12 and CXCR4 protein staining was detected by immunohistochemical analyses of normal and pathological testes, and no apparent phosphorylation differences could be identified to implicate MAPK (MEK1/2, ERK1/2), STAT3, AKT, or ERK in pathway signaling. The human seminoma-derived cell line, TCam-2 (83) was also used by McIver to investigate CXCL12 signaling mechanisms and outcomes relevant to TGCTs. Although no significant differences in signaling molecule phosphorylation status, proliferation, or migration were measured, CXCL12 exposure increased TCam-2 cell invasion in a chamber assay (82). While the role and impact of CXCL12 signaling for TGCTs in vivo is unresolved, it remains a key candidate for further investigation. Studies examining the atypical receptor, CXCR7, and alternative CXCR4 ligands such as MIF may be required to ascertain the contributions of this pathway to testicular neoplasia.

Several highly significant findings implicate abnormal TGF $\beta$ superfamily signaling in TGCT biology. A zebrafish model arising from genetic disruption of BMP signaling (inactivating mutation in the type IB BMP receptor, encoded by alk6b) exhibited impaired spermatogonial differentiation and overgrowth of undifferentiated germ cells, analogous to events considered to underpin human TGCT initiation (84). Examination of Smad1/5/8 in human germ cell neoplasias showed that the less differentiated subtypes, including seminomas, lacked nuclear SMAD 1/5/8 which indicates the absence of canonical BMP signaling; by contrast, more differentiated tumor types display this signaling $(84,85)$. The potential involvement of activin A signaling in TGCTs was demonstrated through immunohistochemical localization of activin type I (ALK2 and ALK4) and type II receptors (ActRIIB) in GCNIS, seminoma and non-seminoma cells (86). Nuclear phospho-SMAD2/3 signal was present in all seminoma samples, indicating active activin/TGF $\beta$ signaling in these tumors, however, a subset of seminoma specimens exhibited expression of betaglycan or the inhibin alpha subunit, both of which block activin signaling and are normally only produced in somatic cells (87). These observations highlight the likelihood that individual tumors have different TGF $\beta$ signaling activities. Furthermore, elevated TGCT risk was associated with a SNP in the INHA gene, which encodes the inhibin alpha subunit (88), though its relationship to altering activin bioactivity remains to be elucidated. This is an interesting avenue to address, because the bioactivity levels of activin in the developing mouse testis have a great impact on germ and somatic cell function [reviewed in Ref. $(9,10)]$.

In vitro studies addressing the impact of TGF $\beta$ superfamily signaling on testicular tumors have explored its potential as a target to restrict testicular tumor growth. An organ culture strategy was applied using small fragments $\left(1 \mathrm{~mm}^{3}\right)$ of primary tumor materials in $30 \mu \mathrm{l}$ hanging drop cultures (89), for parallel analyses of molecular and histological outcomes, with maintenance of cell viability and proliferation for at least 7 days in normal and neoplastic human testis samples (90). GWAS identified that KITL polymorphisms represent one of the highest risk factors for testicular neoplasia $(91,92)$, thus regulation of this signaling pathway may be a logical target for therapeutic intervention. The
KIT Ligand (encoded by KITL, also known as Stem Cell Factor or SCF) is produced by Sertoli cells in the testis, and it signals via the KIT receptor tyrosine kinase that is found on germ cells at specific developmental stages (PGCs, gonocytes, differentiated spematogonia) and Leydig cells (all ages) to regulate their functions. Activin A bioactivity regulates synthesis of KIT and/ or KITL, including in the testis (93-96), and hanging drop culture of testicular fragments in Activin A resulted in downregulation of both KIT mRNA and protein in a seminoma sample (90). The specific impact on KIT signaling in seminoma cells has yet to be addressed. This culture approach could be used for patientspecific testing of treatments and offers a powerful investigative tool for studying cytokine impact in the intact cellular milieu of TGCTs.

The TCam-2 seminoma cell line has enabled important mechanistic investigations of TGF $\beta$ superfamily member functions. Exposure to BMP4 and retinoic acid increased activin receptor transcript levels (ACTRIA, ACTRIIA, and ACTRIIB) and enhanced TCam-2 cell survival and/or proliferation, whereas activin A reduced $A C T R I B$ and did not affect overall survival or proliferation (97). Factors that support human embryonic stem cell differentiation into the endodermal lineage, namely FGF4 and its co-factor heparin, induced the expression of mixed nonseminoma tumor cell markers in TCam-2 cells (98). A combination of TGF $\beta 1, \mathrm{FGF} 4$, and EGF could mediate this outcome, and intriguingly, a BMP signaling blockade was identified as a potential initiating event, based on SMAD phosphorylation patterns. These findings from independent laboratories implicate TGF $\beta$ superfamily signaling as central to controlling TGCT cell behavior, supporting the concept that dysregulated TGF $\beta$ superfamily signaling may elevate the risk of TGCT emergence.

These outcomes relate to the impact of changing cytokine levels and functionality within the tumor microenvironment on tumor cell fate and differentiation. In this regard, the commonly observable dichotomy of cytokine actions may be of particular relevance. TGF $\beta 1$ is one example of an ambivalent cytokine. It is classically regarded as anti-inflammatory, anti-tumorigenic and anti-proliferative, but may under certain conditions exhibit contradictory effects, both oncogenic and tumor-suppressing, depending on the cellular context (99) As these culture studies indicated, activin A or TGF $\beta 1$ signaling in testis cancer may restrict seminoma growth by promoting cellular differentiation, thus further efforts to elucidate the functional interplay of these ligands with other cytokines in the tumor microenvironment will be informative.

\section{Cytokines As Mediators of Crosstalk between Immune Cells and TGCTs}

Infiltrating immune cells are common in various tumors, including TGCTs, contributing to the milieu of cytokines and chemokines that comprise the tumor microenvironment (TME). Important crosstalk between tumor-infiltrating immune cells and cancer cells may reinforce the development of a TME which is optimal for tumor survival and expansion. As described in Section "Cytokine Signaling in Germline Cells," maintenance of the testicular environment for production of sperm is dependent on cytokines secreted by both testicular somatic cells (Sertoli, 
Leydig, peritubular) and resident immune cells. Additionally, some typically "protective" cytokines may, under pathological conditions, negatively impact on testis function and physiology. Whereas many studies have classified the immune cell types that are abundant in testicular tumors, few have assessed the composition of the accompanying cytokine milieu, and hence this important characteristic of the testis cancer microenvironment is poorly understood.

$\mathrm{T}$ cells and macrophages are typical cellular components of testicular tumors (60); by contrast, the presence and roles of DC, as important antigen-presenting cells (APC), remains largely unknown. Under certain conditions, nascent tumor cells escape regulation by the host immune system by inducing APC malfunction, thus hijacking immune surveillance, and in turn initiating immunosuppressive cell recruitment to create a tumor-tolerant microenvironment. Zheng et al. (67) assessed the presence of DC subsets in human seminomas. Significantly higher numbers of CD11c+ myeloid DC ( $\mathrm{mDC}$ ) were found in tumor tissues compared to healthy controls, with a proportion of $\mathrm{mDC}$ presenting an immature phenotype, potentially associated with cancer progression. The $\mathrm{CD} 11 \mathrm{c}+\mathrm{mDC}$ expressed indoleamine-2,3-dioxygenase (IDO, a regulator of T cell development), VEGF and IL4 (immune tolerance cytokines), as well as IL6 and IL23a (pro-inflammatory cytokines that can be involved in Th17 phenotype skewing) but not TGF $\beta 1$ or IL10 (frequently involved in anti-tumor immune responses). In contrast to other studies, significantly higher numbers of IL17+ (potentially Th17 cells) and FoxP3+ (regulatory $\mathrm{T}$ cells) cells were detected in seminomas compared to controls. This result led the authors to propose that a shift in the testicular TME toward a Th2-driven immune response, induced by IL4+ CD11c+ mDC, enables TGCT immune escape via immune suppression.

Bialas et al. (100) also examined both pro- and anti-inflammatory cytokines in seminomas. IL6 and TNFR2 transcripts were both significantly increased in testis cancer, whereas IL10 and TNFR1 levels remained largely similar to respective controls. A pro-proliferative effect of IL6 in testis cancer was suggested, contrasting the outcomes of in vitro treatments of seminiferous tubules in which IL6 was shown to induce normal germ cell apoptosis. By contrast, IL10 was proposed to maintain an immune-tolerant testicular environment. These conclusions align with knowledge of IL6 as a cell growth stimulating factor in other organs/diseases (101) and the known immunosuppressive properties of IL10 (102). However, no further examination of IL6 as a potential testis-tumor promoting factor or its underlying signaling pathways has been conducted.

Our group also studied testis cancer patient samples, combining a more comprehensive analysis of immune cell subtypes in the context of measurements of cytokine transcripts in the surrounding TME (61). This allowed a more extensive examination of immune cell subtypes and functions directly associated with measurements of the specific testis cancer cytokine milieu. Significantly higher levels of transcripts encoding pro-inflammatory cytokines IL1 $\beta$ and TNF matched an extensive recruitment of macrophages (CD68+) and/or DCs (CD11c+) in testis cancer samples. In seminomas, significantly increased levels of IL2 and IFN $\gamma$ were detected, indicating the likelihood of $\mathrm{T}$ cell functional polarization toward a Th1-driven immune response (103). Expression of Th2-related, anti-inflammatory cytokines in testis cancer samples was either not different (IL4) or significantly decreased (IL5, IL13, IL23a) compared to that found in nonneoplastic controls, suggesting that this cytokine milieu may dominate in physiological circumstances to maintain testicular immune privilege and normal spermatogenesis. Adding to the knowledge of the TGF $\beta$ superfamily in testis cancer, TGF $\beta 1$ was also significantly higher in testis cancer samples. The approach of combining cell type enumeration with cytokine analysis (61) also provided mechanistic insights about the prominent presence of B cells selectively in seminoma samples which had earlier led to the proposal that B cells may be pivotal to the immunopathology of testicular cancer (104). Klein measured greatly elevated transcript levels of both IL6, the most important B cell activating factor $(61,105)$, and CXCL13, which encodes a key factor for B cell recruitment. Moreover, a similar increase in both IL6 and CXCL13 transcripts was documented for two samples with localized GCNIS, suggesting that IL6 may function in the early stages of neoplastic progression.

Further work by Klein et al. (106) created a co-culture system to examine the contributions of different cell types to the testis cancer cytokine TME, using TCam-2 cells to represent neoplastic germ cells (seminoma) and peripheral blood monocytic cells (blood-derived immune cells), as a surrogate for testis cancerinfiltrating immune cells. The cytokine pattern observed after $24 \mathrm{~h}$ of co-culture was similar to that documented in ex vivo seminoma samples (106). Intriguingly, this appeared to be initiated by the TCam- 2 cells only following direct contact with immune cells, with IL6 measured at significantly higher levels in TCam-2 cells than in PBMCs recovered from the co-cultures. A model depicting the progressive changes in testicular immune cell populations during the progression from healthy, tumor-free to seminomatous germ cell neoplasia in relationship to local production of cytokines is presented in Figure 3 [adapted from Ref. (107)].

Given the cumulative data on the link between IL6 and testis cancer, an experimental immunotherapeutic approach targeting IL6 could provide knowledge of the clinical applicability of these findings. IL6 archetypically signals through the JAK/STAT signaling pathway, with STAT3 phosphorylation indicative of active signaling via the IL6R. Dysregulated IL6 production has been identified in several cancers, often positively correlated with tumor growth and invasive behaviors (108). The anti-IL6R antibody Tocilizumab, which blocks both membrane-bound and soluble IL6R isoforms, has undergone in vitro testing to evaluate its effects on cancer cell lines. Similar investigations in testis cancer primary samples or with available cell lines may yield insights regarding the potential of immune-therapeutic options for testis cancer patients.

\section{Inflammatory Conditions of the Testis: How Frequent and How Important Are They?}

Infection and inflammation of the reproductive tract are accepted as important etiological factors of male infertility $(109,110)$. 

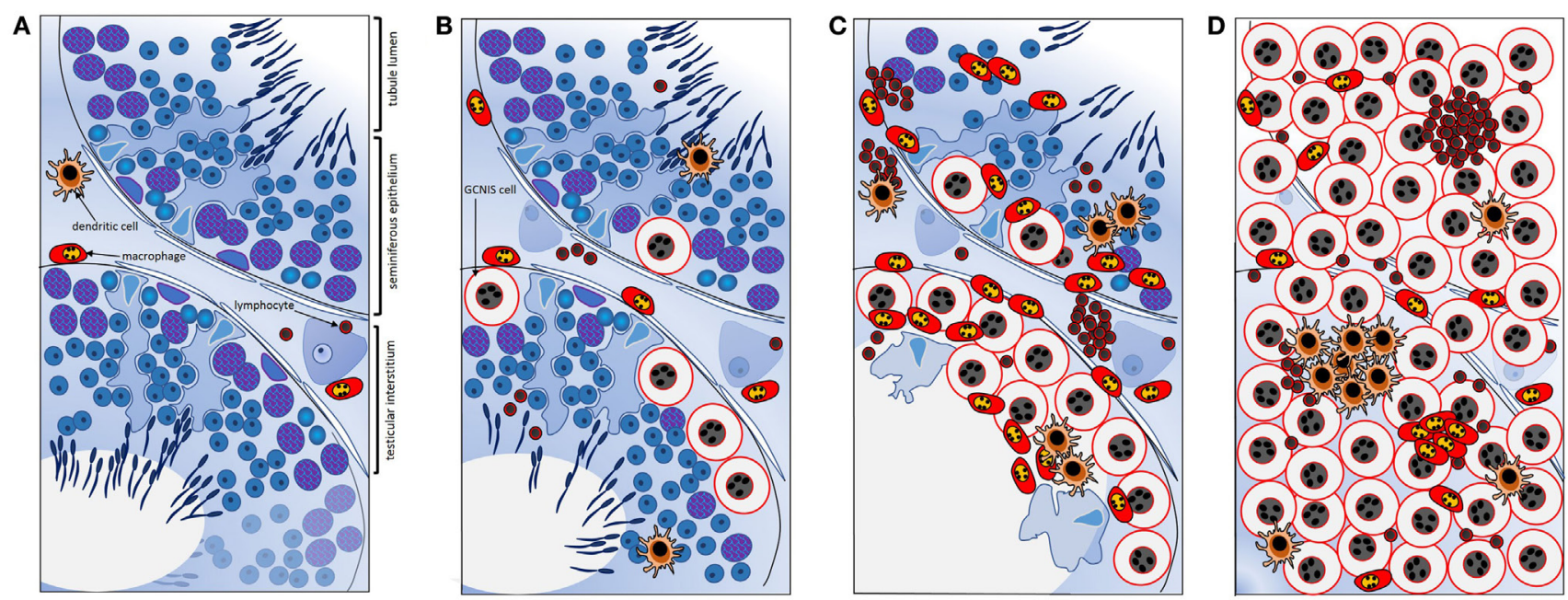

FIGURE 3 | Schematic summary of key transitions documented relating to cytokines and immune cells during testicular germ cell tumor progression indicate their involvement in the progressive changes that underpin testicular neoplasia. (A) In normal spermatogenesis, the number of resident immune cells present in the testicular interstitium is low relative to other somatic cell types. (B) Tubules containing even a few GCNIS cells are associated with changes in the cytokine environment; GCNIS cells themselves may be the source of significant interleukin-6 (IL6) and other cytokines that influence immune cell behaviors. (C) As the number of GCNIS cells increase, different types of immune cells infiltrate the testis, and the local cytokine profile transitions to a "neoplastic pattern." Direct contact with immune cells may enhance cytokine production by GCNIS cells, yielding an environment which facilitates blood-testis barrier disruption and tumor progression. (D) In seminoma, many different types of immune cells and immune cell clusters [mainly comprised of B cells and CD11c+ dendritic cells (DCs)] are present, and characteristic "neoplastic" cytokine microenvironment is detectable that likely facilitates tumor progression. IL6 and other cytokines may be crucial as maintenance and progression factors. Adapted from Ref. (107).

Testicular inflammation occurs as a complication of acute epididymitis, which affects approximately 400 per 100,000 males each year (111). In most cases, the disease is unilateral and caused by ascending infections with sexually transmitted bacteria such as Chlamydia trachomatis or common uropathogens such as Escherichia coli (112). Intriguingly, the course of epididymo-orchitis remains unpredictable despite antimicrobial therapy, with a prevalence of irreversible oligo- or azoospermia in 30 and $10 \%$ of patients, respectively (113). Orchitis as a primary de novo inflammatory process evolves as a complication of systemic, predominantly viral infections due to blood-borne dissemination of the pathogen [reviewed in Ref. (114)]. The classical paradigm of this type of orchitis is seen with mumps infection in post-/pubertal males and associated with the risk of testicular atrophy. Notably, a wide range of other viral infections, including Coxsackie viruses, Epstein-Barr, influenza, and human immunodeficiency viruses, can be associated with orchitis (115, 116). Recently, the sequelae of Zika virus infection, including testicular inflammation and deterioration of spermatogenesis, have been delineated in a mouse model (117); however, whether or not Zika-related, overt orchitis occurs in man remains to be elucidated. A predominantly granulomatous, chronic orchitis is known as a manifestation of tuberculosis, syphilis, lepromatous leprosy, and brucellosis (114).

In addition to infectious disease, non-infectious causes of inflammation in the testis, other than neoplasia (see section “Testicular Cancer"), must be considered. Chronic granulomatous orchitis of unknown etiology in elderly men has been classified as "non-specific" or "idiopathic" (114). Moreover, the testis can be involved in systemic autoimmune diseases such as vasculitis or lupus erythematosus (118).

Acute symptomatic orchitis is considered to be rare from the clinical perspective; however, incidents of subacute or chronic, asymptomatic testicular inflammation of infectious, post-infectious, or primarily non-infectious origin may remain largely obscure, despite important functional consequences for male fertility. For example, systematic re-examination of testicular biopsies from infertile patients revealed asymptomatic focal inflammatory lesions in approximately $30 \%$ of cases (114). In adult men who underwent orchidectomy because of cryptorchidism, focal lymphocytic infiltrates were found in over $40 \%$ of the specimens (119). These findings highlight the likelihood that pre-existent testicular disorders may be accompanied by inflammation. However, autoimmune orchitis, which can be induced in experimental animals as a vigorous organ-specific immune response by active immunization with homologous testis homogenates, has not yet been established as a clinical entity [reviewed in Ref. $(24,120,121)$ ].

Upon assessment of these clinical observations, it is apparent that testicular immune privilege does not preclude effective innate and adaptive immune responses to infectious pathogens or other noxae. As a hallmark of inflammatory disease of the human testis, recruitment of non-resident immune cells can be observed. Infiltrating inflammatory cells obviously overcome the immunosuppressive milieu and indicate a profound disturbance of the delicate local immune regulation (122). Apart from edema, histopathology of both acute bacterial epididymo-orchitis and viral orchitis reveals massive infiltration 
of the interstitial compartment and seminiferous tubules with immune cells, including neutrophils $(115,123)$. Perpetuated chronic (sterile) inflammation is characterized by multifocal peritubular lymphocytic infiltrates which are also encountered in testicular biopsies of infertile men. Increased numbers of immune cells (mast cells and macrophages) accumulate specifically in the seminiferous tubule walls, which frequently appear fibrotic. Affected tubules show degeneration of the germinal epithelium sparing few spermatogonia and Sertoli cells; concomitant thickening of the lamina propria may result in complete fibrosis of the tubules accompanied by increased collagen production ("tubular shadows") (123). Notably, these are typical morphological features of experimental autoimmune orchitis (EAO) (124-127). Consistent with relevant animal models, infiltrating lymphocytes are primarily effector memory T cells (CD45R0+; CD4+>CD8+), which are accompanied by increased numbers of non-resident CD68+ macrophages and mast cells $(58,123,128-132)$. In contrast to EAO or infectious orchitis in rodents, the role of CD11c+ cells (putative DCs) seen in low numbers in non-neoplastic human testicular inflammation is unclear $(61,126)$.

As outlined above, there is growing evidence from animal models that numerous autocrine and paracrine mediators play a dual role in the testis $(24,50,133)$. Resident macrophages and mast cells as well as non-immune somatic cells such as Sertoli cells have been shown to produce a plethora of cytokines, including both pro- and anti-inflammatory molecules such as IL1 $\beta$, IL6, TNF $\alpha, I F N \gamma$, members of the TGF $\beta$ family, and IL10 (134-137). Compared to murine models, however, data illustrating the involvement of cytokines in human testis physiology and disease are scarce. There is suggestive evidence that maintenance of the testicular immune privilege and normal spermatogenesis are favored by a Th2-balanced cytokine milieu (IL4, IL5, IL13), in contrast to the Th1-driven immune environment of neoplasia (61). As reported by Bialas et al. (100), mRNA levels of anti-inflammatory IL10 remain largely unchanged in various testicular pathologies. Together with IL10, changes in TGF $\beta 1$ levels may reflect the presence or expansion of immunoregulatory $\mathrm{T}$ cell subtypes (e.g., CD4+CD25+Foxp3+Treg cells) (52, 138-140), which are yet to be identified and explored in the human testis. Moreover, exposure to Th2-related cytokines, IL10, and TGF $\beta$ polarizes testicular macrophages toward the tolerogenic M2 phenotype $(54,73)$. M2 macrophages themselves secrete high amounts of anti-inflammatory (IL10, TGF $\beta$ ) and low levels of proinflammatory cytokines (IL12, TNF) $(54,141)$.

Testicular inflammation obviously occurs despite the presence of immunoregulatory cells and anti-inflammatory cytokines. In this context, IL23a-producing CD68+ and CD11c+ cells most likely orchestrate Th17 cells, detected using immunohistochemistry along with their key product IL17a in testis biopsies from infertile men with signs of inflammation $(131,142)$. We have observed increased levels of pro-inflammatory cytokine mRNAs, such as those encoding IL1 $\beta$, TNF, and IFN $\gamma$, in selected specimens with disturbed spermatogenesis and inflammatory lesions using PCR (61). In contrast to neoplasia, overall quantitative analysis revealed only minor differences between biopsies with hypospermatogenesis/ focal infiltrates and normal testes, and somewhat conflicting results were also obtained for IL17a transcript levels (61). This may reflect the inherent heterogeneity of human testis biopsy samples and the highly variable distribution of focal cell populations.

With regard to the recruitment, trafficking, and activation of leukocytes to the site of inflammation, chemokines, chemokine receptors and adhesion molecules are decisive mediators. In murine EAO, upregulation of cell adhesion molecules (CD31, CD44, CD106), in conjunction with increased levels of chemokines (MCP-1, macrophage inflammatory proteins $1 \alpha$ and $1 \beta$ ) and chemokine receptors (CCR2, CCR5), contribute to the formation of a chemotactic gradient within the testis, causing characteristic peri- and intratubular leukocyte infiltration $(136,143)$. DCs isolated from EAO rat testes showed upregulated expression of CCR7, which is responsible for the migration of these APC to the draining lymph nodes (144). Together with IL6, MCP-1 was also described as a factor released by human testicular peritubular cells upon activation of TNF receptors (145).

In a cross-platform gene expression analysis of testicular biopsies with spermatogenic failure, Spiess et al. (146) identified an increase of transcripts encoding the high-affinity IgE receptor and the mast cell-related fractalkine receptor (CX3CR1). This observation is in line with increased numbers of mast cells consistently found in testicular biopsies from infertile men with impaired spermatogenesis $(61,129,132)$. In addition to proinflammatory cytokines, such as TNF and IL6, mast cells produce the serine protease tryptase, which may act as a potent mitogen for fibroblasts and peritubular cells resulting in enhanced synthesis of collagen and subsequent tubular fibrosis $(59,147,148)$. Activation of the tryptase receptor proteinase-activated receptor- 2 on peritubular cells in vitro led to expression of MCP-1, cyclooxygenase-2, and TGF $\beta 2$ (149).

Besides cytokines and chemokines, other pro-inflammatory molecules, such as high-mobility group box protein 1, are involved in the regulation of inflammatory reactions in rat and human testis and might serve as targets for therapeutic intervention (150). In addition, involvement of galectin-1, activins, and inhibin in the development of testicular immunopathology is documented (127, 151-153).

There is compelling evidence that inflammatory infiltrates are associated with disruption of the blood-testis barrier in affected seminiferous tubules $(120,133)$. As a key proinflammatory cytokine in testicular immunopathology, IL6 has been described to perturb the integrity of the blood-testis barrier in rats (154). Recent results indicate that IL6 acts through inhibiting protein degradation or activating phosphorylated ERK in Sertoli cells (155). Via the transcription factor Zfp637 it can directly affect spermatogonia and, thus, interferes with germ cell differentiation or degeneration. Along with IL6 and its receptor, TNF/TNFR1, Fas/FasL and Bax/Bcl-2 systems have all been shown to be involved in germ cell apoptosis in rat EAO $(78,144,156)$. Among tight junction proteins in the seminiferous tubules, the highly conserved claudin-11 may represent a putative target (157). 


\section{KNOWLEDGE OF TESTICULAR CYTOKINES USED TO ADDRESS KEY CLINICAL ISSUES}

\section{Cytokines As Non-Invasive Diagnostic Tools}

Cytokines and chemokines produced by resident immune cells and non-immune somatic cells in the testis are also found further downstream in the reproductive tract. The vast majority have been detected in human seminal plasma, and pro-inflammatory molecules such as IL6, IL8, and TNF $\alpha$ are routinely used as markers of male genital tract inflammation (158). Taking the composition of human semen into consideration, however, changes in seminal cytokine levels are not compartment-specific and do not necessarily reflect testicular (immuno-) pathologies (110, 159). As an example, KITL has been proposed as testis-specific seminal marker for spermatogenesis (160). Ligands in the TGF $\beta$ superfamily, inhibin B and anti-Mullerian hormone, produced by Sertoli cells are typically used to assess testicular function, as their production reflects the presence or absence of ongoing spermatogenesis $(161,162)$.

With regard to the high expression of IL6 associated with testicular germ cell neoplasia (i.e., seminoma), the possible diagnostic (and/or prognostic) value of corresponding levels in seminal plasma and/or peripheral blood remains to be elucidated $(61,106)$. Proteomics of testicular fluids characterizing different pathologies (163) may help to identify new organ-specific immunoregulatory molecules or diagnostics to indicate the level of function within the seminiferous epithelium; these may also occur in seminal plasma and/or peripheral blood. Moreover, testis-specific molecular signatures could be developed by combining different cytokines and related molecules in a multiplex assay approach.

\section{Cytokines As Therapeutic Agents or Targets}

As discussed above (see section "Testicular Cancer"), the involvement of IL6 in testis cancer and the suggested immuno-editing by neoplastic germ cells $(61,100,106)$ renders this pro-inflammatory and pro-proliferative molecule a putative therapeutic target. Additional cytokine pathways involved with establishment and maintenance of the tumor microenvironment may be strong candidates for adjunct therapeutics, but much work remains to be done to reach this outcome.

In patients with acute mumps orchitis, $I F N \alpha 2 B$ with putative antiviral activity was administered in order to prevent or minimize testicular damage $(164,165)$. The therapeutic efficacy of this concept, however, was not convincing; in a follow-up study, testicular biopsies revealed total atrophy of seminiferous tubules in $38 \%$ of patients and partial atrophy in $16 \%(165)$.

As outlined above (see section "Inflammatory Conditions of the Testis: How Frequent and How Important Are They?"), TNF represents a hallmark of non-neoplastic testicular inflammation. Early experiments using the adoptive transfer of EAO in mice revealed that recipient pre-treatment with neutralizing antibody to TNF, but not neutralizing antibody to $I F N \gamma$, attenuated autoimmune orchitis (166). This concept, however, has not been revisited in a clinical setting for men suffering non-infectious (or post-infectious) orchitis, although available TNF inhibitors are routinely used for a wide range of chronic inflammatory diseases. To date, therapeutic attempts to improve chronic low-grade testicular inflammation have been limited to orally administered glucocorticosteroids, non-steroidal anti-inflammatory drugs such as cyclooxygenase inhibitors as well as mast cell stabilizers $(110,114)$.

Other therapeutic avenues will no doubt be identified, as research dedicated to the preservation of fertility in cancer patients are developed. Encouraging results have been obtained from the administration of granulocyte colony stimulating factor (G-CSF) to male rodents prior to the application of previously sterilizing doses of the chemotherapeutic agent, busulfan $(167,168)$. Important clues to its mode of action in this circumstance may emerge as we better understand how local immune cell functions influence spermatogenesis, as G-CSF is typically administered to support neutrophil function. Future developments may include application of anti-fibrotic treatments to prevent long-term testicular damage, emerging from investigations of agents that block TGF $\beta$ and activin signaling in the testis and epididymis during key stages of infection [e.g., Ref. $(127,169)]$.

\section{Potential Testicular Adverse Effects of Immunomodulatory Interventions}

In recent years, a growing number of small molecules with immunomodulatory properties and biologics have become available and are routinely used in chronic inflammatory diseases as well as hematologic and other malignancies. Considering major improvements in survival rates and quality of life, potential longterm effects on male reproductive health are a matter of concern. Some examples are discussed below.

Inhibitors of TNF comprise monoclonal antibodies (e.g., infliximab) or fusion proteins (e.g., etanercept). Although effects of infliximab on spermatogenesis could be shown in vitro, no impairment of male fertility was observed clinically in patients with rheumatoid disease (170-173). Ustekinumab, a monoclonal IgG1 antibody that binds to the p40 subunit of IL12 and IL23, revealed no reproductive toxicity in male cynomolgus monkeys, whereas data from clinical studies are missing [reviewed in Ref. (174)]. For the upcoming range of antibodies targeting IL17A (e.g., in patients with psoriasis), neither pre-clinical nor clinical data concerning adverse effects on testicular and overall male reproductive function are available (175). Whereas the selective blockade of the IL1 receptor by anakinra does not seem to impair male fertility, semen quality even improved during treatment in patients suffering auto-inflammatory Muckle-Wells syndrome (176).

Animal studies with rituximab, a chimeric (mouse/human) anti-CD20 antibody achieving B cell depletion, showed no deleterious effects on reproductive organs (174). By contrast, administration of the anti-CTLA4 antibody ipilimumab, which interferes with $\mathrm{T}$ cell activation, showed a negative effect on testicular volume in pre-clinical experiments, whereas patients treated with this antibody are at risk of developing autoimmune endocrinopathies (i.e., hypophysitis) $(177,178)$. 
Considering that alterations in the KITL/KIT system may cause disorders of the neuro-endocrine-immunological network, tyrosine kinases (mTOR inhibitors) such as imatinib should not be ignored. A small number of studies have examined the effect of imatinib administration on rodent spermatogenesis, with only one addressing fertility outcomes. Despite some measurable effects on testis growth and function when delivered to juveniles, healthy offspring were fathered by treated males (179, 180). Despite a lack of controlled clinical studies, case reports indicate that this drug can impair sperm quality, even resulting in azoospermia (181). On the other hand, imatinib decreased mast cell counts and tryptase release in patients with severe asthma (182).

\section{CONCLUDING REMARKS}

Consolidation of knowledge regarding the roles of cytokines in development and maintenance of the testis is integral to making advances in diagnosis and treatment for male infertility, a condition which affects up to 1 in 20 couples. This review has provided examples of how information from basic research in non-mammalian species can address this need and highlighted the profound impact of immune cell function on normal and pathogenic functions in the testis. Future studies that detail the testis-specific function of specific cytokines and chemokines, and reveal their interactions with other cellular signaling pathways, will be essential to improve clinical management for patients with

\section{REFERENCES}

1. De Kretser DM, O’Bryan MK, Loveland KL. Spermatogenesis. 7th ed. In: Larry Jameson J, De Groot LJ, editors. Endocrinology: Adult \& Pediatric. Philadelphia: Elsevier (2016). p. 2325-53.e9.

2. Gustafsson K, Söder O, Pöllänen P, Ritzén EM. Isolation and partial characterization of an interleukin-1-like factor from rat testis interstitial fluid. J Reprod Immunol (1988) 14:139-50. doi:10.1016/0165-0378(88)90065-4

3. Syed V, Söder O, Arver S, Lindh M, Khan S, Ritzén EM. Ontogeny and cellular origin of an interleukin-1-like factor in the reproductive tract of the male rat. Int J Androl (1988) 11:437-47. doi:10.1111/j.1365-2605.1988. tb01016.x

4. Hedger MP, Meinhardt A. Cytokines and the immune-testicular axis. J Reprod Immunol (2003) 58:1-26. doi:10.1016/S0165-0378(02) 00060-8

5. Wang G, Yu Y, Sun C, Liu T, Liang T, Zhan L, et al. STAT3 selectively interacts with Smad3 to antagonize TGF- $\beta$. Oncogene (2016) 35(33):4388-98. doi:10.1038/onc.2015.446

6. Wang Z, Sun J, Feng Y, Tian X, Wang B, Zhou Y. Oncogenic roles and drug target of CXCR4/CXCL12 axis in lung cancer and cancer stem cell. Tumour Biol (2016) 37(7):8515-28. doi:10.1007/s13277-016-5016-z

7. Luo K. Signaling cross talk between TGF- $\beta /$ Smad and other signaling pathways. Cold Spring Harb Perspect Biol (2017) 9(1). doi:10.1101/cshperspect. a022137

8. Ware CF. The TNF receptor superfamily in immune regulation. Immunol Rev (2011) 244:5-8. doi:10.1111/j.1600-065X.2011.01065.x

9. Young JC, Wakitani S, Loveland KL. TGF- $\beta$ superfamily signaling in testis formation and early male germline development. Semin Cell Dev Biol (2015) 45:94-103. doi:10.1016/j.semcdb.2015.10.029

10. Loveland KL, Hedger MP. Activins and inhibins in Sertoli cell biology: implications for testis development and function. In: Griswold M, editor. Sertoli Cell Biology. USA: Elsevier Science (2015). p. 201-21.

11. Chen W, Ten Dijke P. Immunoregulation by members of the TGF $\beta$ superfamily. Nat Rev Immunol (2016) 16(12):723-40. doi:10.1038/nri.2016.112 male infertility or with other conditions in which spermatogenesis may be impaired by the disease or its therapies.

\section{AUTHOR CONTRIBUTIONS}

All authors contributed to the text and edited the manuscript.

\section{ACKNOWLEDGMENTS}

The authors would like to thank Penny Whiley for generating Figure 1.

\section{FUNDING}

This work was supported by the Deutsche Forschungsgemeinschaft (DFG) and Monash University as part of the International Research Training Group between Justus Liebig University of Giessen and Monash University, Melbourne (GRK 1871/1) on "Molecular pathogenesis on male reproductive disorders." KL was supported by NHMRC grants (Fellowship, ID1079646 and Project, ID1081987); $\mathrm{MH}$ was supported by NHMRC grants (Fellowship, ID1020269 and Project Grant ID1063843); KL and MH received support from the Victorian State Government Operational Infrastructure Scheme. MB and HCS were supported by the LOEWE focus group "MIBIE" (Male infertility during infection \& inflammation), an excellence initiative of the German state government of Hessen.

12. Loveland KL, Robertson DM. The TGF $\beta$ superfamily in sertoli cell biology. In: Griswold M, Skinner M, editors. Sertoli Cell Biology. USA: Elsevier Science (2005). p. 227-47.

13. Itman $\mathrm{C}$, Mendis S, Barakat B, Loveland KL. All in the family: TGF- $\beta$ family action in testis development. Reproduction (2006) 132:233-46. doi:10.1530/rep.1.01075

14. Stanton PG. Regulation of the blood-testis barrier. Semin Cell Dev Biol (2016) 59:166-73. doi:10.1016/j.semcdb.2016.06.018

15. Monsivais D, Matzuk MM, Pangas SA. The TGF- $\beta$ family in the reproductive tract. Cold Spring Harb Perspect Biol (2017) 9(10):a022251. doi:10.1101/ cshperspect.a022251

16. Meinhardt A, Bacher M, McFarlane JR, Metz CN, Seitz J, Hedger MP, et al. Macrophage migration inhibitory factor production by Leydig cells: evidence for a role in the regulation of testicular function. Endocrinology (1996) 137:5090-5. doi:10.1210/endo.137.11.8895383

17. Cohen PE, Hardy MP, Pollard JW. Colony-stimulating factor-1 plays a major role in the development of reproductive function in male mice. Mol Endocrinol (1997) 11:1636-50. doi:10.1210/mend.11.11.0009

18. Oatley JM, Oatley MJ, Avarbock MR, Tobias JW, Brinster RL. Colony stimulating factor 1 is an extrinsic stimulator of mouse spermatogonial stem cell self-renewal. Development (2009) 136(7):1191-9. doi:10.1242/dev.032243

19. Meikle AW, Cardoso de Sousa JC, Dacosta N, Bishop DK, Samlowski WE. Direct and indirect effects of murine interleukin-2, gamma interferon, and tumor necrosis factor on testosterone synthesis in mouse Leydig cells. J Androl (1992) 13:437-43.

20. Bauché F, Stéphan JP, Touzalin AM, Jégou B. In vitro regulation of an inducible-type NO synthase in the rat seminiferous tubule cells. Biol Reprod (1998) 58:431-8. doi:10.1095/biolreprod58.2.431

21. Aubry F, Habasque C, Satie AP, Jégou B, Samson M. Expression and regulation of the CC-chemokine monocyte chemoattractant protein-1 in rat testicular cells in primary culture. Biol Reprod (2000) 62:1427-35. doi:10.1095/ biolreprod62.5.1427

22. Gerdprasert O, O’Bryan MK, Nikolic-Paterson DJ, Sebire K, de Kretser DM, Hedger MP. Expression of monocyte chemoattractant protein-1 and 
macrophage colony-stimulating factor in normal and inflamed rat testis. Mol Hum Reprod (2002) 8:518-24. doi:10.1093/molehr/8.6.518

23. O'Bryan MK, Hedger MP. Inflammatory networks in the control of spermatogenesis. Chronic inflammation in an immunologically privileged tissue? Adv Exp Med Biol (2008) 636:92-114. doi:10.1007/978-0-387-09597-4_6

24. Hedger MP. Toll-like receptors and signalling in spermatogenesis and testicular responses to inflammation - a perspective. J Reprod Immunol (2011) 88:130-41. doi:10.1016/j.jri.2011.01.010

25. Hedger MP, Winnall WR. Regulation of activin and inhibin in the adult testis and the evidence for functional roles in spermatogenesis and immunoregulation. Mol Cell Endocrinol (2012) 359:30-42. doi:10.1016/j.mce.2011.09.031

26. Issigonis M, Tulina N, de Cuevas M, Brawley C, Sandler L, Matunis E. JAK-STAT signal inhibition regulates competition in the Drosophila testis stem cell niche. Science (2009) 326(5949):153-6. doi:10.1126/science.1176817

27. Amoyel M, Anderson J, Suisse A, Glasner J, Bach EA. Socs36E controls niche competition by repressing MAPK signaling in the Drosophila testis. PLoS Genet (2016) 12(1):e1005815. doi:10.1371/journal.pgen.1005815

28. Tarayrah L, Herz HM, Shilatifard A, Chen X. Histone demethylase dUTX antagonizes JAK-STAT signaling to maintain proper gene expression and architecture of the Drosophila testis niche. Development (2013) 140(5): 1014-23. doi:10.1242/dev.089433

29. Tarayrah L, Li Y, Gan Q, Chen X. Epigenetic regulator Lid maintains germline stem cells through regulating JAK-STAT signaling pathway activity. Biol Open (2015) 4(11):1518-27. doi:10.1242/bio.013961

30. Deshpande G, Nouri A, Schedl P. Wnt signaling in sexual dimorphism. Genetics (2016) 202(2):661-73. doi:10.1534/genetics.115.177857

31. Hasan S, Hétié P, Matunis EL. Niche signaling promotes stem cell survival in the Drosophila testis via the JAK-STAT target DIAP1. Dev Biol (2015) 404(1):27-39. doi:10.1016/j.ydbio.2015.04.017

32. Shapiro-Kulnane L, Smolko AE, Salz HK. Maintenance of Drosophila germline stem cell sexual identity in oogenesis and tumorigenesis. Development (2015) 142(6):1073-82. doi:10.1242/dev.116590

33. Ma Q, Wawersik M, Matunis EL. The Jak-STAT target Chinmo prevents sex transformation of adult stem cells in the Drosophila testis niche. Dev Cell (2014) 31(4):474-86. doi:10.1016/j.devcel.2014.10.004

34. Stine RR, Greenspan LJ, Ramachandran KV, Matunis EL. Coordinate regulation of stem cell competition by Slit-Robo and JAK-STAT signaling in the Drosophila testis. PLoS Genet (2014) 10(11):e1004713. doi:10.1371/journal. pgen.1004713

35. Wu J, Jester WF Jr, Orth JM. Short-type PB-cadherin promotes survival of gonocytes and activates JAK-STAT signalling. Dev Biol (2005) 284(2): 437-50. doi:10.1016/j.ydbio.2005.05.042

36. Yamazaki T, Kanzaki M, Kamidono S, Fujisawa M. Effect of erythropoietin on Leydig cell is associated with the activation of Stat5 pathway. Mol Cell Endocrinol (2004) 213(2):193-8. doi:10.1016/j.mce.2003.10.031

37. Pawig L, Klasen C, Weber C, Bernhagen J, Noels H. Diversity and interconnections in the CXCR4 chemokine receptor/ligand family: molecular perspectives. Front Immunol (2015) 6:429. doi:10.3389/fimmu.2015.00429

38. Ara T, Nakamura $Y$, Egawa $T$, Sugiyama $T$, Abe K, Kishimoto $T$, et al. Impaired colonization of the gonads by primordial germ cells in mice lacking a chemokine, stromal cell-derived factor-1 (SDF-1). Proc Natl Acad Sci U S A (2003) 100(9):5319-23. doi:10.1073/pnas.0730719100

39. Molyneaux KA, Zinszner H, Kunwar PS, Schaible K, Stebler J, Sunshine MJ, et al. The chemokine SDF1/CXCL12 and its receptor CXCR4 regulate mouse germ cell migration and survival. Development (2003) 130(18):4279-86. doi:10.1242/dev.00640

40. Stebler J, Spieler D, Slanchev K, Molyneaux KA, Richter U, Cojocaru V, et al. Primordial germ cell migration in the chick and mouse embryo: the role of the chemokine SDF-1/CXCL12. Dev Biol (2004) 272(2):351-61. doi:10.1016/j.ydbio.2004.05.009

41. Kanatsu-Shinohara M, Inoue K, Takashima S, Takehashi M, Ogonuki N, Morimoto $\mathrm{H}$, et al. Reconstitution of mouse spermatogonial stem cell niches in culture. Cell Stem Cell (2012) 11(4):567-78. doi:10.1016/j.stem.2012.06.011

42. Yang Q-E, Kim K, Kaucher A, Oatley MJ, Oatley JM. CXCL12-CXCR4 signaling is required for the maintenance of mouse spermatogonial stem cells. J Cell Sci (2013) 126:1009-20. doi:10.1242/jcs.119826

43. Westernströer B, Terwort N, Ehmcke J, Wistuba J, Schlatt S, Neuhaus N. Profiling of Cxcl12 receptors, $\mathrm{Cxcr} 4$ and $\mathrm{Cxcr} 7$ in murine testis development and a spermatogenic depletion model indicates a role for Cxcr7 in controlling
Cxcl12 activity. PLoS One (2014) 9(12):e112598. doi:10.1371/journal. pone. 0112598

44. Asri A, Sabour J, Atashi A, Soleimani M. Homing in hematopoietic stem cells: focus on regulatory role of CXCR7 on SDF1a/CXCR4 axis. EXCLI J (2016) 15:134-43. doi:10.17179/excli2014-585

45. Westernströer B, Langenstroth D, Kliesch S, Troppmann B, Redmann K, Macdonald J, et al. Developmental expression patterns of chemokines CXCL11, CXCL12 and their receptor CXCR7 in testes of common marmoset and human. Cell Tissue Res (2015) 361(3):885-98. doi:10.1007/ s00441-015-2164-1

46. Alampour-Rajabi S, El Bounkari O, Rot A, Müller-Newen G, Bachelerie F, Gawaz M, et al. MIF interacts with CXCR7 to promote receptor internalization, ERK1/2 and ZAP-70 signaling, and lymphocyte chemotaxis. FASEB J (2015) 29(11):4497-511. doi:10.1096/fj.15-273904

47. Meinhardt A, Bacher M, Wennemuth G, Eickhoff R, Hedger M. Macrophage migration inhibitory factor (MIF) as a paracrine mediator in the interaction of testicular somatic cells. Andrologia (2000) 32(1):46-8.

48. Wennemuth G, Aumüller G, Bacher M, Meinhardt A. Macrophage migration inhibitory factor-induced $\mathrm{Ca}(2+)$ response in rat testicular peritubular cells. Biol Reprod (2000) 62(6):1632-9. doi:10.1095/biolreprod62.6.1632

49. Huleihel M, Abofoul-Azab M, Abarbanel Y, Einav I, Levitas E, Lunenfeld E. Production of macrophage inhibitory factor (MIF) by primary Sertoli cells; its possible involvement in migration of spermatogonial cells. J Cell Physiol (2017) 232(10):2869-77. doi:10.1002/jcp.25718

50. Meinhardt A, Hedger MP. Immunological, paracrine and endocrine aspects of testicular immune privilege. Mol Cell Endocrinol (2011) 335:60-8. doi:10.1016/j.mce.2010.03.022

51. Kaur G, Thompson LA, Dufour JM. Sertoli cells - immunological sentinels of spermatogenesis. Semin Cell Dev Biol (2014) 30:36-44. doi:10.1016/j. semcdb.2014.02.011

52. Fijak M, Damm LJ, Wenzel JP, Aslani F, Walecki M, Wahle E, et al. Influence of testosterone on inflammatory response in testicular cells and expression of transcription factor Foxp3 in T cells. Am J Reprod Immunol (2015) 7:12-25. doi:10.1111/aji.12363

53. Ferguson TA, Griffith TS. A vision of cell death: Fas ligand and immune privilege 10 years later. Immunol Rev (2006) 213:228-38. doi:10.1111/j. 1600-065X.2006.00430.x

54. Winnall WR, Muir JA, Hedger MP. Rat resident testicular macrophages have an alternatively activated phenotype and constitutively produce interleukin-10 in vitro. J Leukoc Biol (2011) 90:133-43. doi:10.1189/jlb.1010557

55. Bryniarski K, Szczepanik M, Maresz K, Ptak M, Ptak W. Subpopulations of mouse testicular macrophages and their immunoregulatory function. Am J Reprod Immunol (2004) 52:27-35. doi:10.1111/j.1600-0897.2004.00178.x

56. Wang J, Wreford NG, Lan HY, Atkins R, Hedger MP. Leukocyte populations of the adult rat testis following removal of the Leydig cells by treatment with ethane dimethane sulfonate and subcutaneous testosterone implants. Biol Reprod (1994) 51:551-61. doi:10.1095/biolreprod51.3.551

57. Tompkins AB, Hutchinson P, de Kretser DM, Hedger MP. Characterization of lymphocytes in the adult rat testis by flow cytometry: effects of activin and transforming growth factor $\beta$ on lymphocyte subsets in vitro. Biol Reprod (1998) 58:943-51. doi:10.1095/biolreprod58.4.943

58. Frungieri MB, Calandra RS, Lustig L, Meineke V, Köhn FM, Vogt HJ, et al. Number, distribution pattern, and identification of macrophages in the testes of infertile men. Fertil Steril (2002) 78(2):298-306. doi:10.1016/ S0015-0282(02)03206-5

59. Frungieri MB, Weidinger S, Meineke V, Kohn FM, Mayerhofer A. Proliferative action of mast-cell tryp-tase is mediated by PAR2, COX2, prostaglandins, and PPARgamma: possible relevance to human fibrotic disorders. Proc Natl Acad Sci U S A (2002) 99:15072-7. doi:10.1073/pnas.232422999

60. Hvarness T, Nielsen JE, Almstrup K, Skakkebaek NE, Rajpert-De Meyts E, Claesson MH. Phenotypic characterisation of immune cell infiltrates in testicular germ cell neoplasia. J Reprod Immunol (2013) 100(2):135-45. doi:10.1016/j.jri.2013.10.005

61. Klein B, Haggeney T, Fietz D, Indumathy S, Loveland KL, Hedger M, et al. Specific immune cell and cytokine characteristics of human testicular germ cell neoplasia. Hum Reprod (2016) 31:2192-202. doi:10.1093/humrep/ dew211

62. Hedger MP. Macrophages and the immune responsiveness of the testis. J Reprod Immunol (2002) 57:19-34. doi:10.1016/S0165-0378(02)00016-5 
63. Raburn DJ, Coquelin A, Reinhart AJ, Hutson JC. Regulation of the macrophage population in postnatal rat testis. J Reprod Immunol (1993) 24:139-51. doi:10.1016/0165-0378(93)90016-B

64. Gaytan F, Bellido C, Aguilar E, van RN. Requirement for testicular macrophages in Leydig cell proliferation and differentiation during prepubertal development in rats. J Reprod Fertil (1994) 102:393-9. doi:10.1530/jrf.0.1020393

65. DeFalco T, Bhattacharya I, Williams AV, Sams DM, Capel B. Yolk-sacderived macrophages regulate fetal testis vascularization and morphogenesis. Proc Natl Acad Sci U S A (2014) 111(23):E2384-93. doi:10.1073/ pnas. 1400057111

66. DeFalco T, Potter SJ, Williams AV, Waller B, Kan MJ, Capel B. Macrophages contribute to the spermatogonial niche in the adult testis. Cell Rep (2015) 12(7):1107-19. doi:10.1016/j.celrep.2015.07.015

67. Zheng W, Chen J, Liu C, Zhou J, Zhu C, Li M, et al. Immature CD11c+ myeloid dendritic cells with inflammatory and regulatory cytokine profile in human seminoma. Int J Clin Exp Pathol (2016) 9(3):2803-19.

68. Winnall WR, Hedger MP. Phenotypic and functional heterogeneity of the testicular macrophage population: a new regulatory model. J Reprod Immunol (2013) 97:147-58. doi:10.1016/j.jri.2013.01.001

69. Martinez FO, Sica A, Mantovani A, Locati M. Macrophage activation and polarization. Front Biosci (2008) 13:453-61. doi:10.2741/2692

70. Locati M, Mantovani A, Sica A. Macrophage activation and polarization as an adaptive component of innate immunity. Adv Immunol (2013) 120: 163-84. doi:10.1016/B978-0-12-417028-5.00006-5

71. Xiong Y, Hales DB. Expression, regulation, and production of tumor necrosis factor-a in mouse testicular interstitial macrophages in vitro. Endocrinology (1993) 133:2568-73. doi:10.1210/endo.133.6.8243279

72. Mosser DM, Edwards JP. Exploring the full spectrum of macrophage activation. Nat Rev Immunol (2008) 8:958-69. doi:10.1038/nri2448

73. Gordon S. Alternative activation of macrophages. Nat Rev Immunol (2003) 3:23-35. doi:10.1038/nri978

74. Gordon S, Taylor PR. Monocyte and macrophage heterogeneity. Nat Rev Immunol (2005) 5:953-64. doi:10.1038/nri1733

75. Bhushan S, Meinhardt A. The macrophages in testis function. J Reprod Immunol (2017) 19:107-12. doi:10.1016/j.jri.2016.06.008

76. Genin M, Clement F, Fattaccioli A, Raes M, Michiels C. M1 and M2 macrophages derived from THP- 1 cells differentially modulate the response of cancer cells to etoposide. BMC Cancer (2015) 15:577. doi:10.1186/s12885-015-1546-9

77. Gordon S, Plüddemann A. Tissue macrophages: heterogeneity and functions. BMC Biol (2017) 15(1):53. doi:10.1186/s12915-017-0392-4

78. Rival C, Theas MS, Guazzone VA, Lustig L. Interleukin-6 and IL-6 receptor cell expression in testis of rats with autoimmune orchitis. J Reprod Immunol (2006) 70:43-58. doi:10.1016/j.jri.2005.10.006

79. Rajpert-De Meyts E, McGlynn KA, Okamoto K, Jewett MA, Bokemeyer C. Testiculargerm cell tumours. Lancet (2016)387(10029):1762-74.doi:10.1016/ S0140-6736(15)00991-5

80. Skakkebaek NE, Rajpert-De Meyts E, Main KM. Testicular dysgenesis syndrome: an increasingly common developmental disorder with environmental aspects. Hum Reprod (2001) 16:972-8.

81. Giannoulatou E, Maher GJ, Ding Z, Gillis AJM, Dorssers LCJ, Hoischen A, et al. Whole-genome sequencing of spermatocytic tumors provides insights into the mutational processes operating in the male germline. PLoS One (2017) 12(5):e0178169. doi:10.1371/journal.pone.0178169

82. McIver SC, Loveland KL, Roman SD, Nixon B, Kitazawa R, McLaughlin EA. The chemokine CXCL12 and its receptor CXCR4 are implicated in human seminoma metastasis. Andrology (2013) 1(3):517-29. doi:10.1111/j.20472927.2013.00081.x

83. de Jong J, Stoop H, Gillis AJ, Hersmus R, van Gurp RJ, van de Geijn GJ, et al. Further characterization of the first seminoma cell line TCam-2. Genes Chromosomes Cancer (2008) 47(3):185-96. doi:10.1002/gcc.20520

84. Neumann JC, Chandler GL, Damoulis VA, Fustino NJ, Lillard K, Looijenga L, et al. Mutation in the type IB bone morphogenetic protein receptor Alk6b impairs germ-cell differentiation and causes germ-cell tumors in zebrafish. Proc Natl Acad Sci U S A (2011) 108(32):13153-8. doi:10.1073/pnas.1102311108

85. Fustino N, Rakheja D, Ateek CS, Neumann JC, Amatruda JF. Bone morphogenetic protein signalling activity distinguishes histological subsets of paediatric germ cell tumours. Int J Androl (2011) 34(4 Pt 2):e218-33. doi:10.1111/j.1365-2605.2011.01186.x
86. Dias V, Meachem S, Rajpert-De Meyts E, McLachlan R, Manuelpillai U, Loveland KL. Activin receptor subunits in normal and dysfunctional adult human testis. Hum Reprod (2008) 23:412-20. doi:10.1093/humrep/dem343

87. Dias VL, Rajpert-De Meyts E, McLachlan R, Loveland KL. Analysis of activin/TGFB-signaling modulators within the normal and dysfunctional adult human testis reveals evidence of altered signaling capacity in a subset of seminomas. Reproduction (2009) 138(5):801-11. doi:10.1530/REP-09-0206

88. Purdue MP, Graubard BI, Chanock SJ, Rubertone MV, Erickson RL, McGlynn KA. Genetic variation in the inhibin pathway and risk of testicular germ cell tumors. Cancer Res (2008) 68(8):3043-8. doi:10.1158/00085472.CAN-07-5852

89. Szczepny A, Hogarth CA, Young J, Loveland KL. Hedgehog signalling in the testis examined using a novel culture method. Biol Reprod (2009) 80:258-63. doi:10.1095/biolreprod.108.067926

90. Jørgensen A, Young J, Nielsen JE, Joensen UN, Toft BG, Rajpert-De Meyts E, et al. Hanging drop cultures of human testis and testis cancer samples used to investigate activin treatment effects in a preserved niche. Br J Cancer (2014) 110(10):2604-14. doi:10.1038/bjc.2014.160

91. Kanetsky PA, Mitra N, Vardhanabhuti S, Li M, Vaughn DJ, Letrero R, et al. Common variation in KITLG and at $5 \mathrm{q} 31.3$ predisposes to testicular germ cell cancer. Nat Genet (2009) 41(7):811-5. doi:10.1038/ng.393

92. Litchfield K, Levy M, Orlando G, Loveday C, Law PJ, Migliorini G, et al. Identification of 19 new risk loci and potential regulatory mechanisms influencing susceptibility to testicular germ cell tumor. Nat Genet (2017) 49(7): 1133-40. doi:10.1038/ng.3896

93. Hino M, Nishizawa Y, Tatsumi N, Tojo A, Morii H. Down-modulation of c-kit mRNA and protein expression by erythroid differentiation factor/activin A. FEBS Lett (1995) 374(1):69-71. doi:10.1016/0014-5793(95)01078-S

94. Mithraprabhu S, Mendis S, Meachem SJ, Tubino L, Matzuk MM, Brown CW, et al. Activin bioactivity affects germ cell differentiation in the postnatal mouse testis in vivo. Biol Reprod (2010) 82:980-90. doi:10.1095/ biolreprod.109.079855

95. Coutts SM, Childs AJ, Fulton N, Collins C, Bayne RA, McNeilly AS, et al. Activin signals via SMAD2/3 between germ and somatic cells in the human fetal ovary and regulates kit ligand expression. Dev Biol (2008) 314(1):189-99. doi:10.1016/j.ydbio.2007.11.026

96. Childs AJ, Anderson RA. Activin A selectively represses expression of the membrane-bound isoform of Kit ligand in human fetal ovary. Fertil Steril (2009) 92(4):1416-9. doi:10.1016/j.fertnstert.2009.03.095

97. Young JC, Jaiprakash A, Mithraprabhu S, Itman C, Kitazawa R, Looijenga LH, et al. TCam-2 seminoma cell line exhibits characteristic foetal germ cell responses to TGF-beta ligands and retinoic acid. Int J Androl (2011) 34(4 Pt2):e204-17. doi:10.1111/j.1365-2605.2011.01170.x

98. Nettersheim D, Gillis AJ, Looijenga LH, Schorle H. TGF- $\beta 1$, EGF and FGF4 synergistically induce differentiation of the seminoma cell line TCam-2 into a cell type resembling mixed non-seminoma. Int J Androl (2011) 34(4 Pt2):e189-203. doi:10.1111/j.1365-2605.2011.01172.x

99. KubiczkovaL, Sedlarikova L, HajekR, SevcikovaS.TGF- $\beta$-an excellentservant but a bad master. J Transl Med (2012) 10:183. doi:10.1186/1479-5876-10-183

100. Bialas M, Fiszer D, Rozwadowska N, Kosicki W, Jedrzejczak P, Kurpisz M. The role of IL-6, IL-10, TNF-alpha and its receptors TNFR1 and TNFR2 in the local regulatory system of normal and impaired human spermatogenesis. Am J Reprod Immunol (2009) 62(1):51-9. doi:10.1111/j.1600-0897.2009.00711.x

101. Cai Q, Huang H, Bai B, Lin S, Gao Y, Xia Y, et al. IL-6 promotes cell proliferation and antiapoptosis through activation of the JAK/STAT3 pathway in patients with NK/T - cell lymphoma and correlates with poor treatment outcome. Blood (2013) 122:1758.

102. Mittal SK, Roche PA. Suppression of antigen presentation by IL-10. Curr Opin Immunol (2015) 34:22-7. doi:10.1016/j.coi.2014.12.009

103. Disis ML. Immune regulation of cancer. J Clin Oncol (2010) 28:4531-8. doi:10.1200/JCO.2009.27.2146

104. Willis SN, Mallozzi SS, Rodig SJ, Cronk KM, McArdel SL, Caron T, et al. The microenvironment of germ cell tumours harbors a prominent antigen-driven humoral response. J Immunol (2009) 182:3310-7. doi:10.4049/ jimmunol.0803424

105. Mauri C, Bosma A. Immune regulatory function of B cells. Annu Rev Immunol (2012) 30:221-41. doi:10.1146/annurev-immunol-020711-074934

106. Klein B, Schuppe HC, Bergmann M, Hedger MP, Loveland BE, Loveland KL. An in vitro model demonstrates the potential of neoplastic human germ cells 
to influence the tumour microenvironment. Andrology (2017) 5(4):763-70. doi:10.1111/andr.12365

107. Klein B. Immunocharacteristics of Testicular Germ Cell Cancers - Revelation of a New Key Network? Ph.D. thesis, Justus Liebig University of Giessen and Monash University, Giessen, Germany (2017).

108. Guo Y, Xu F, Lu T, Duan Z, Zhang Z. Interleukin-6 signaling pathway in targeted therapy for cancer. Cancer Treat Rev (2012) 38(7):904-10. doi:10.1016/j.ctrv.2012.04.007

109. Rowe PJ, Comhaire FH, Hargreave TB, Mahmoud AMA. WHO Manual for the Standarized Investigation, Diagnosis and Management of the Infertile Male. Cambridge: Cambridge University Press (2000).

110. Schuppe HC, Pilatz A, Hossain H, Diemer T, Wagenlehner F, Weidner W. Urogenital infection as a risk factor for male infertility. Dtsch Arztebl Int (2017) 114(19):339-46. doi:10.3238/arztebl.2017.0339

111. Nicholson A, Rait G, Murray-Thomas T, Hughes G, Mercer CH, Cassell J. Management of epididymo-orchitis in primary care: results from a large UK primary care database. Br J Gen Pract (2010) 60:e407-22. doi:10.3399/bjgp10X532413

112. Pilatz A, Hossain H, Kaiser R, Mankertz A, Schuttler CG, Domann E, et al. Acute epididymitis revisited: impact of molecular diagnostics on etiology and contemporary guideline recommendations. Eur Urol (2015) 68:428-35. doi:10.1016/j.eururo.2014.12.005

113. Rusz A, Pilatz A, Wagenlehner F, Linn T, Diemer T, Schuppe HC, et al. Influence of urogenital infections and inflammation on semen quality and male fertility. World J Urol (2012) 30:23-30. doi:10.1007/s00345-011-0726-8

114. Schuppe HC, Meinhardt A, Allam JP, Bergmann M, Weidner W, Haidl G. Chronic orchitis: a neglected cause of male infertility? Andrologia (2008) 40:84-91. doi:10.1111/j.1439-0272.2008.00837.x

115. Mikuz G, Damjanov I. Inflammation of the testis, epididymis, peritesticular membranes, and scrotum. Pathol Annu (1982) 17(Pt 1):101-28.

116. Dejucq N, Jegou B. Viruses in the mammalian male genital tract and their effects on the reproductive system. Microbiol Mol Biol Rev (2001) 65:208-31. doi:10.1128/MMBR.65.2.208-231.2001

117. Govero J, Esakky P, Scheaffer SM, Fernandez E, Drury A, Platt DJ, et al. Zika virus infection damages the testes in mice. Nature (2016) 540(7633): 438-42. doi:10.1038/nature20556

118. Nistal M, Paniagua R. Non-neoplastic diseases of the testis. In: Eble JN, editor. Urologic Surgical Pathology. St. Louis: Mosby (1997). p. 458-565.

119. Nistal M, Riestra ML, Paniagua R. Focal orchitis in undescended testes: discussion of pathogenetic mechanisms of tubular atrophy. Arch Pathol Lab Med (2002) 126:64-9. doi:10.1043/0003-9985(2002)126<0064:FOIUT>2.0.CO;2

120. Fijak M, Meinhardt A. The testis in immune privilege. Immunol Rev (2006) 213:66-81. doi:10.1111/j.1600-065X.2006.00438.x

121. Naito M, Terayama H, Hirai S, Qu N, Lustig L, Itoh M. Experimental autoimmune orchitis as a model of immunological male infertility. Med Mol Morphol (2012) 45:185-9. doi:10.1007/s00795-012-0587-2

122. Schuppe HC, Meinhardt A. Immune privilege and inflammation of the testis. Chem Immunol Allergy (2005) 88:1-14. doi:10.1159/000087816

123. Schuppe HC, Bergmann M. Inflammatory conditions of the testis. In: Ježek D, editor. Atlas on the Human Testis. London: Springer (2013). p. 113-22.

124. Lustig L, Lourtau L, Perez R, Doncel GF. Phenotypic characterization of lymphocytic cell infiltrates into the testes of rats undergoing autoimmune orchitis. Int J Androl (1993) 16:279-84. doi:10.1111/j.1365-2605.1993.tb01192.x

125. Rival C, Theas MS, Suescun MO, Jacobo P, Guazzone V, van Rooijen N, et al. Functional and phenotypic characteristics of testicular macrophages in experimental autoimmune orchitis. J Pathol (2008) 215:108-17. doi:10.1002/path.2328

126. Guazzone VA, Hollwegs S, Mardirosian M, Jacobo P, Hackstein H, Wygrecka $\mathrm{M}$, et al. Characterization of dendritic cells in testicular draining lymph nodes in a rat model of experimental autoimmune orchitis. Int J Androl (2011) 34:276-89. doi:10.1111/j.1365-2605.2010.01082.x

127. Nicolas N, Michel V, Bhushan S, Wahle E, Hayward S, Ludlow H, et al. Testicular activin and follistatin levels are elevated during the course of experimental autoimmune epididymo-orchitis in mice. Sci Rep (2017) 7:42391. doi:10.1038/srep42391

128. El-Demiry MI, Hargreave TB, Busuttil A, Elton R, James K, Chisholm GD. Immunocompetent cells in human testis in health and disease. Fertil Steril (1987) 48:470-9. doi:10.1016/S0015-0282(16)59421-7

129. Meineke V, Frungieri MB, Jessberger B, Vogt H, Mayerhofer A. Human testicular mast cells contain tryptase: increased mast cell number and altered distribution in the testes of infertile men. Fertil Steril (2000) 74:239-44. doi:10.1016/S0015-0282(00)00626-9

130. Hussein MR, Abou-Deif ES, Bedaiwy MA, Said TM, Mustafa MG, Nada E, et al. Phenotypic characterization of the immune and mast cell infiltrates in the human testis shows normal and abnormal spermatogenesis. Fertil Steril (2005) 83(5):1447-53. doi:10.1016/j.fertnstert.2004.11.062

131. Duan YG, Yu CF, Novak N, Bieber T, Zhu CH, Schuppe HC, et al. Immunodeviation towards a Th17 immune response associated with testicular damage in azoospermic men. Int J Androl (2011) 34:e536-45. doi:10.1111/j. 1365-2605.2010.01137.x

132. Welter H, Köhn FM, Mayerhofer A. Mast cells in human testicular biopsies from patients with mixed atrophy: increased numbers, heterogeneity and expression of cyclooxygenase 2 and prostaglandin D2 synthase. Fertil Steril (2011) 96(2):309-13. doi:10.1016/j.fertnstert.2011.05.035

133. Pérez CV, Theas MS, Jacobo PV, Jarazo-Dietrich S, Guazzone VA, Lustig L. Dual role of immune cells in the testis - protective or pathogenic for germ cells? Spermatogenesis (2013) 3:e23870-1. doi:10.4161/spmg.23870

134. Suescun MO, Rival C, Theas MS, Calandra RS, Lustig L. Involvement of tumor necrosis factor-alpha in the pathogenesis of autoimmune orchitis in rats. Biol Reprod (2003) 68:2114-21. doi:10.1095/biolreprod.102.011189

135. Rival C, Lustig L, Iosub R, Guazzone VA, Schneider E, Meinhardt A, et al. Identification of a dendritic cell population in normal testis and in chronically inflamed testis of rats with autoimmune orchitis. Cell Tissue Res (2006) 324(2):311-8. doi:10.1007/s00441-005-0129-5

136. Guazzone VA, Rival C, Denduchis B, Lustig L. Monocyte chemoattractant protein-1 (MCP-1/CCL2) in experimental autoimmune orchitis. J Reprod Immunol (2003) 60:143-57. doi:10.1016/j.jri.2003.08.001

137. O’Bryan MK, Gerdprasert O, Nikolic-Paterson DJ, Meinhardt A, Muir JA, Foulds LM, et al. Cytokine profiles in the testes of rats treated with lipopolysaccharide reveal localized suppression of inflammatory responses. Am J Physiol Regul Integr Comp Physiol (2005) 288(6):R1744-55. doi:10.1152/ ajpregu.00651.2004

138. Guazzone VA, Jacobo P, Theas MS, Lustig L. Cytokines and chemokines in testicular inflammation: a brief review. Microsc Res Tech (2009) 72(8): 620-8. doi:10.1002/jemt.20704

139. Fijak M, Schneider E, Klug J, Bhushan S, Hackstein H, Schuler G, et al. Testosterone replacement effectively inhibits the development of experimental autoimmune orchitis in rats: evidence for a direct role of testosterone on regulatory T cell expansion. J Immunol (2011) 186:5162-72. doi:10.4049/jimmunol.1001958

140. Walecki M, Eisel F, Klug J, Baal N, Paradowska-Dogan A, Wahle E, et al. Androgen receptor modulates Foxp3 expression in CD4+CD25+Foxp3+ regulatory T-cells. Mol Biol Cell (2015) 26:2845-57. doi:10.1091/mbc. E14-08-1323

141. Bhushan S, Tchatalbachev S, Lu Y, Fröhlich S, Fijak M, Vijayan V, et al. Differential activation of inflammatory pathways in testicular macrophages provides a rationale for their subdued inflammatory capacity. J Immunol (2015) 194(11):5455-64. doi:10.4049/jimmunol.1401132

142. Walsh KP, Mills KHG. Dendritic cells and other determinants of T helper cell polarisation. Trends Immunol (2013) 34(11):521-30. doi:10.1016/j.it.2013.07.006

143. Guazzone VA, Jacobo P, Denduchis B, Lustig L. Expression of cell adhesion molecules, chemokines and chemokine receptors involved in leukocyte traffic in rats undergoing autoimmune orchitis. Reproduction (2012) 143:651-62. doi:10.1530/REP-11-0079

144. Rival C, Guazzone VA, von Wulffen W, Hackstein H, Schneider E, Lustig L, et al. Expression of co-stimulatory molecules, chemokine receptors and proinflammatory cytokines in dendritic cells from normal and chronically inflamed rat testis. Mol Hum Reprod (2007) 13:853-61. doi:10.1093/ molehr/gam067

145. Schell C, Albrecht M, Mayer C, Schwarzer JU, Frungieri MB, Mayerhofer A. Exploring human testicular peritubular cells: identification of secretory products and regulation by tumor necrosis factor-alpha. Endocrinology (2008) 149(4):1678-86. doi:10.1210/en.2007-1064

146. Spiess AN, Feig C, Schulze W, Chalmel F, Cappallo-Obermann H, Primig M, et al. Cross-platform gene expression signature of human spermatogenic failure reveals inflammatory-like response. Hum Reprod (2007) 22(11):2936-46. doi:10.1093/humrep/dem292

147. Albrecht M, Rämsch R, Köhn FM, Schwarzer JU, Mayerhofer A. Isolation and cultivation of human testicular peritubular cells: a new model for the 
investigation of fibrotic processes in the human testis and male infertility. J Clin Endocrinol Metab (2006) 91(5):1956-60. doi:10.1210/jc.2005-2169

148. Mayerhofer A. Human testicular peritubular cells: more than meets the eye. Reproduction (2013) 145:R107-16. doi:10.1530/REP-12-0497

149. Iosub R, Klug J, FijakM,Schneider E, Frohlich S, Blumbach K, et al.Development of testicular inflammation in the rat involves activation of proteinase-activated receptor-2. J Pathol (2006) 208:686-98. doi:10.1002/path.1938

150. Aslani F, Schuppe HC, Guazzone VA, Bhushan S, Wahle E, Lochnit G, et al. Targeting high mobility group box protein 1 ameliorates testicular inflammation in experimental autoimmune orchitis. Hum Reprod (2015) 30:417-31. doi:10.1093/humrep/deu320

151. Pérez CV, Gómez LG, Gualdoni GS, Lustig L, Rabinovich GA, Guazzone VA. Dual roles of endogenous and exogenous galectin-1 in the control of testicular immunopathology. Sci Rep (2015) 5:12259. doi:10.1038/srep12259

152. Gao J, Wang X, Wang Y, Han F, Cai W, Zhao B, et al. Murine Sertoli cells promote the development of tolerogenic dendritic cells: a pivotal role of galectin-1. Immunology (2016) 148:253-65. doi:10.1111/imm.12598

153. Nicolas N, Muir JA, Hayward S, Chen JL, Stanton PG, Gregorevic P, et al. Induction of EAO in mice: responses to elevated circulating levels of the follistatin. Reproduction (2017) 154(3):193-205. doi:10.1530/REP-17-0010

154. Pérez CV, Sobarzo CM, Jacobo PV, Pellizzari EH, Cigorraga SB, Denduchis B, et al. Loss of occludin expression and impairment of blood-testis barrier permeability in rats with autoimmune orchitis: effect of interleukin 6 on Sertoli cell tight junctions. Biol Reprod (2012) 87(5):122. doi:10.1095/ biolreprod.112.101709

155. Zhang H, Yin Y, Wang G, Liu Z, Liu L, Sun F. Interleukin-6 disrupts blood-testis barrier through inhibiting protein degradation or activating phosphorylated ERK in Sertoli cells. Sci Rep (2014) 4:260. doi:10.1038/srep04260

156. Jacobo PV, Fass M, Pérez CV, Jarazo-Dietrich S, Lustig L, Theas MS. Involvement of soluble Fas Ligand in germ cell apoptosis in testis of rats undergoing autoimmune orchitis. Cytokine (2012) 60(2):385-92. doi:10.1016/j.cyto.2012.07.020

157. Stammler A, Lüftner BU, Kliesch S, Weidner W, Bergmann M, MiddendorffR, et al. Highly conserved testicular localization of claudin-11 in normal and impaired spermatogenesis. PLoS One (2016) 11(8):e0160349. doi:10.1371/ journal.pone. 0160349

158. Pilatz A, Hudemann C, Wagenlehner F, Schuppe HC, Diemer T, Weidner W, et al. Seminal cytokines in urogenital disorders - is quantification useful? Urologe A (2013) 52:359-66. doi:10.1007/s00120-013-3141-5

159. Fraczek M, Kurpisz M. Cytokines in the male reproductive tract and their role in infertility disorders. J Reprod Immunol (2015) 108:98-104. doi:10.1016/j. jri.2015.02.001

160. Mauduit C, Hamamah S, Benahmed M. Stem cell factor/c-kit system in spermatogenesis. Hum Reprod Update (1999) 5(5):535-45. doi:10.1093/ humupd/5.5.535

161. Hart RJ, Doherty DA, Keelan JA, McLachlan R, Skakkebaek NE, Norman RJ, et al. Early life events predict adult testicular function; Data derived from the Western Australian (Raine) Birth Cohort. J Clin Endocrinol Metab (2016) 101(9):3333-44. doi:10.1210/jc.2016-1646

162. Bandak M, Jørgensen N, Juul A, Lauritsen J, Kier MGG, Mortensen MS, et al. Reproductive hormones and metabolic syndrome in 24 testicular cancer survivors and their biological brothers. Andrology (2017) 5(4):718-24. doi:10.1111/andr.12355

163. Stanton PG, Foo CF, Rainczuk A, Stephens AN, Condina M, O’Donnell L, et al. Mapping the testicular interstitial fluid proteome from normal rats. Proteomics (2016) 16(17):2391-402. doi:10.1002/pmic.201600107

164. Ku JH, Kim YH, Jeon YS, Lee NK. The preventive effect of systemic treatment with interferon-alpha2B for infertility from mumps orchitis. BJU Int (1999) 7:839-42.

165. Yeniyol CO, Sorguc S, Minareci S, Ayder AR. Role of interferon-alpha-2B in prevention of testicular atrophy with unilateral mumps orchitis. Urology (2000) 55:931-3. doi:10.1016/S0090-4295(00)00491-X

166. Yule TD, Tung KS. Experimental autoimmune orchitis induced by testis and sperm antigen-specific $\mathrm{T}$ cell clones: an important pathogenic cytokine is tumor necrosis factor. Endocrinology (1993) 133(3):1098-107. doi:10.1210/ endo.133.3.8103448

167. Benavides-Garcia R, Joachim R, Pina NA, Mutoji KN, Reilly MA, Hermann BP. Granulocyte colony-stimulating factor prevents loss of spermatogenesis after sterilizing busulfan chemotherapy. Fertil Steril (2015) 103(1):270-80.e8. doi:10.1016/j.fertnstert.2014.09.023

168. Kotzur T, Benavides-Garcia R, Mecklenburg J, Sanchez JR, Reilly M, Hermann BP. Granulocyte colony-stimulating factor (G-CSF) promotes spermatogenic regeneration from surviving spermatogonia after high-dose alkylating chemotherapy. Reprod Biol Endocrinol (2017) 15(1):7. doi:10.1186/ s12958-016-0226-1

169. Michel V, Duan Y, Stoschek E, Bhushan S, Middendorff R, Young JM, et al. Uropathogenic Escherichia coli causes fibrotic remodelling of the epididymis. J Pathol (2016) 240(1):15-24. doi:10.1002/path.4748

170. Suominen JS, Wang Y, Kaipia A, Toppari J. Tumor necrosis factor-alpha (TNF-alpha) promotes cell survival during spermatogenesis, and this effect can be blocked by a TNF-alpha antagonist. Eur J Endocrinol (2004) 151(5):629-40. doi:10.1530/eje.0.1510629

171. Villiger PM, Caliezi G, Cottin V, Förger F, Senn A, Østensen M. Effects of TNF antagonists on sperm characteristics in patients with spondyloarthritis. Ann Rheum Dis (2010) 69:1842-4. doi:10.1136/ard.2009.127423

172. Micu MC, Micu R, Surd S, Gîrlovanu M, Bolboacă SD, Østensen M. TNF-alpha inhibitors do not impair sperm quality in males with ankylosing spondylitis after short-term or long-term treatment. Rheumatology (Oxford) (2014) 53:1250-5. doi:10.1093/rheumatology/keu007

173. Ramonda R, Foresta C, Ortolan A, Bertoldo A, Oliviero F, Lorenzin M, et al. Influence of tumor necrosis factor $\alpha$ inhibitors on testicular function and semen in spondyloarthritis patients. Fertil Steril (2014) 101(2):359-65. doi:10.1016/j.fertnstert.2013.10.048

174. Grunewald S, Jank A. New systemic agents in dermatology with respect to fertility, pregnancy, and lactation. J Dtsch Dermatol Ges (2015) 13(4):277-89. doi:10.1111/ddg. 12596

175. Götestam Skorpen C, Hoeltzenbein M, Tincani A, Fischer-Betz R, Elefant E, Chambers $\mathrm{C}$, et al. The EULAR points to consider for use of antirheumatic drugs before pregnancy, and during pregnancy and lactation. Ann Rheum Dis (2016) 75(5):795-810. doi:10.1136/annrheumdis-2015-208840

176. Tran TA, Kone-Paut I, Marie I, Ninet J, Cuisset L, Meinzer U. MuckleWells syndrome and male hypofertility: a case series. Semin Arthritis Rheum (2012) 42:327-31. doi:10.1016/j.semarthrit.2012.03.005

177. Dillard T, Yedinak CG, Alumkal J, Fleseriu M. Anti-CTLA-4 antibody therapy associated autoimmune hypophysitis: serious immune related adverse events across a spectrum of cancer subtypes. Pituitary (2010) 13:29-38. doi:10.1007/ s11102-009-0193-z

178. Day D, Hansen AR. Immune-related adverse events associated with immune checkpoint inhibitors. BioDrugs (2016) 30(6):571-84. doi:10.1007/ s40259-016-0204-3

179. Nurmio M, Toppari J, Zaman F, Andersson AM, Paranko J, Söder O, et al. Inhibition of tyrosine kinases PDGFR and C-Kit by imatinib mesylate interferes with postnatal testicular development in the rat. Int J Androl (2007) 30(4):366-76. doi:10.1111/j.1365-2605.2007.00755.x

180. Nurmio M, Kallio J, Toppari J, Jahnukainen K. Adult reproductive functions after early postnatal inhibition by imatinib of the two receptor tyrosine kinases, c-kit and PDGFR, in the rat testis. Reprod Toxicol (2008) 25(4):442-6. doi:10.1016/j.reprotox.2008.03.004

181. Shash E, Bassi S, Cocorocchio E, Colpi GM, Cinieri S, Peccatori FA. Fatherhood during imatinib. Acta Oncol (2011) 50:734-5. doi:10.3109/028 4186X.2011.577562

182. Cahill KN, Katz HR, Cui J, Lai J, Kazani S, Crosby-Thompson A, et al. KIT inhibition by imatinib in patients with severe refractory asthma. $N$ Engl J Med (2017) 376(20):1911-20. doi:10.1056/NEJMoa1613125

Conflict of Interest Statement: The authors declare that the research was conducted in the absence of any commercial or financial relationships that could be construed as a potential conflict of interest.

Copyright (c) 2017 Loveland, Klein, Pueschl, Indumathy, Bergmann, Loveland, Hedger and Schuppe. This is an open-access article distributed under the terms of the Creative Commons Attribution License (CC BY). The use, distribution or reproduction in other forums is permitted, provided the original author(s) or licensor are credited and that the original publication in this journal is cited, in accordance with accepted academic practice. No use, distribution or reproduction is permitted which does not comply with these terms. 